\title{
2020 Seoul Consensus on the Diagnosis and Management of Gastroesophageal Reflux Disease
}

\author{
Hye-Kyung Jung, ${ }^{1}$ Chung Hyun Tae, ${ }^{1}$ Kyung Ho Song, ${ }^{2}$ Seung Joo Kang, ${ }^{3}$ Jong Kyu Park, ${ }^{4}$ Eun Jeong Gong, ${ }^{4}$ Jeong Eun Shin, ${ }^{5}$ \\ Hyun Chul Lim, ${ }^{6}$ Sang Kil Lee, ${ }^{7}$ Da Hyun Jung, ${ }^{7}$ Yoon Jin Choi, ${ }^{7}$ Seung In Seo, Joon Sung Kim, ${ }^{8}$ Jung Min Lee, ${ }^{10}$ Beom Jin Kim, ${ }^{11}$ \\ Sun Hyung Kang, ${ }^{12}$ Chan Hyuk Park, ${ }^{13}$ Suck Chei Choi, ${ }^{14}$ Joong Goo Kwon, ${ }^{15}$ Kyung Sik Park, ${ }^{16}$ Moo In Park, ${ }^{17}$ Tae Hee Lee, ${ }^{18}$ \\ Seung Young Kim, ${ }^{19}$ Young Sin Cho, ${ }^{20}$ Han Hong Lee, ${ }^{21}$ Kee Wook Jung, ${ }^{22}$ Do Hoon Kim, ${ }^{22}$ Hee Seok Moon, ${ }^{23}$ Hirota Miwa, ${ }^{24}$ \\ Chien-Lin Chen, ${ }^{25}$ Sutep Gonlachanvit, ${ }^{26}$ Uday C Ghoshal, ${ }^{27}$ Justin C Y Wu ${ }^{28}$ Kewin T H Siah, ${ }^{29,30}$ Xiaohua Hou, ${ }^{31}$ Tadayuki Oshima, $^{32}$ \\ Mi-Young Choi, ${ }^{33}$ and Kwang Jae Lee ${ }^{34 *}$; The Korean Society of Neurogastroenterology and Motility
}

\begin{abstract}
${ }^{1}$ Department of Internal Medicine, Ewha Womans University College of Medicine, Seoul, Korea; ${ }^{2}$ Division of Gastroenterology, Department of Internal Medicine, CHA Ilsan Medical Center, CHA University School of Medicine, Ilsan, Jeollabuk-do, Korea; ${ }^{3}$ Department of Internal Medicine, Seoul National University Hospital Gangnam Center, Seoul, Korea; ${ }^{4}$ Department of Internal Medicine, Gangneung Asan Hospital, University of Ulsan College of Medicine, Gangneung, Gangwon-do, Korea; ${ }^{5}$ Department of Internal Medicine, Dankook University College of Medicine, Cheonan, Chungcheongnam-do, Korea; ${ }^{6}$ Department of Internal Medicine, Yongin Severance Hospital, Yonsei University College of Medicine, Yongin, Gyeonggi-do, Korea; ${ }^{7}$ Division of Gastroenterology, Department of Internal Medicine, Severance Hospital, Yonsei University College of Medicine, Seoul, Korea; ${ }^{8}$ Division of Gastroenterology, Department of Internal Medicine, Kangdong Sacred Heart Hospital, Hallym University College of Medicine, Seoul, Korea; ${ }^{9}$ Division of Gastroenterology, Department of Internal Medicine, Incheon St. Mary's Hospital, College of Medicine, The Catholic University of Korea, Incheon, Korea; ${ }^{10}$ Digestive Disease Center, CHA Gangnam Medical Center, CHA University, Seoul, Korea; ${ }^{11}$ Department of Internal Medicine, Chung-Ang University College of Medicine, Seoul, Korea; ${ }^{12}$ Department of Gastroenterology, Chungnam National University Hospital, Chungnam National University School of Medicine, Daejeon, Korea; ${ }^{13}$ Department of Internal Medicine, Hanyang University Guri Hospital, Hanyang University College of Medicine, Guri, Gyeonggi-do, Korea; ${ }^{14}$ Department of Internal Medicine and Digestive Disease Research Institute, Wonkwang University School of Medicine, Iksan, Jeollabuk-do, Korea; ${ }^{15}$ Department of Internal Medicine, Daegu Catholic University School of Medicine, Daegu, Korea; ${ }^{16}$ Department of Internal Medicine, Keimyung University School of Medicine, Daegu, Korea; ${ }^{17}$ Department of Internal Medicine, Kosin University College of Medicine, Busan, Korea; ${ }^{18}$ Department of Internal Medicine, Soonchunhyang University Seoul Hospital, Seoul, Korea; ${ }^{19}$ Department of Internal Medicine, College of Medicine, Korea University, Seoul, Korea; ${ }^{20}$ Division of Gastroenterology, Department of Internal Medicine, Soonchunhyang University Cheonan, Hospital, Cheonan, Chungcheongnamdo, Korea; ${ }^{21}$ Department of Surgery, Seoul St. Mary's Hospital, College of Medicine, The Catholic University of Korea, Seoul, Korea; ${ }^{22}$ Department of Gastroenterology, Asan Medical Center, University of Ulsan College of Medicine, Seoul, Korea; ${ }^{23}$ Department of Internal Medicine, Chungnam National University School of Medicine, Daejeon, Korea; ${ }^{24}$ Division of Gastroenterology and Hepatology, Department of Internal Medicine, Hyogo College of Medicine, Nishinomiya, Hyogo, Japan; ${ }^{25}$ Institute of Medical Sciences, Tzu Chi University, and Department of Public Health, College of Medicine, Tzu Chi University, Hualien City, Taiwan; ${ }^{26}$ Center of Excellence on Neurogastroenterology and Motility, Department of Medicine, Faculty of Medicine, Chulalongkorn University, Bangkok, Thailand; ${ }^{27}$ Departments of Gastroenterology, Sanjay Gandhi Postgraduate Institute of Medical Science, Lucknow, India; ${ }^{28}$ Institute of Digestive Disease, Department of Medicine and Therapeutics, Faculty of Medicine, The Chinese University of Hong Kong; China; ${ }^{29}$ Department of Medicine, Yong Loo Lin School of Medicine, National University of Singapore, Singapore; ${ }^{30}$ Division of Gastroenterology and Hepatology, University Medicine Cluster, National University Hospital, Singapore; ${ }^{31}$ Department of Gastroenterology, Union Hospital, Tongji Medical College, Huazhong University of Science and Technology, Wuhan, Hubei Province, China; ${ }^{32}$ Division of Gastroenterology and Hepatology, Department of Internal Medicine, Hyogo College of Medicine, Nishinomiya, Japan; ${ }^{33}$ Division of Healthcare Technology Assessment Research, National Evidence-based Healthcare Collaborating Agency, Seoul, Korea; and ${ }^{34}$ Department of Gastroenterology, Ajou University School of Medicine, Suwon, Gyeonggi-do, Korea
\end{abstract}

Gastroesophageal reflux disease (GERD) is a condition in which gastric contents regurgitate into the esophagus or beyond, resulting in either troublesome symptoms or complications. GERD is heterogeneous in terms of varied manifestations, test findings, and treatment responsiveness. GERD diagnosis can be established with symptomatology, pathology, or physiology. Recently the Lyon consensus defined the "proven GERD" with concrete evidence for reflux, including advanced grade erosive esophagitis (Los Angeles classification grades C and or D esophagitis), long-segment Barrett's mucosa or peptic strictures on endoscopy or distal esophageal acid exposure time $>6 \%$ on 24-hour ambulatory pH-impedance monitoring. However, some Asian researchers have different opinions on whether the same standards should be applied to the Asian population. The prevalence of GERD is increasing in Asia. The present evidence-based guidelines were developed using a systematic review and meta-analysis approach. In GERD with typical symptoms, a proton pump inhibitor test can be recommended as a sensitive, cost-effective, and practical test for GERD diagnosis. 
Based on a meta-analysis of 19 estimated acid-exposure time values in Asians, the reference range upper limit for esophageal acid exposure time was 3.2\% (95\% confidence interval, 2.7-3.9\%) in the Asian countries. Esophageal manometry and novel impedance measurements, including mucosal impedance and a post-reflux swallow-induced peristaltic wave, are promising in discrimination of GERD among different reflux phenotypes, thus increasing its diagnostic yield. We also propose a long-term strategy of evidence-based GERD treatment with proton pump inhibitors and other drugs.

(J Neurogastroenterol Motil 2021;27:453-481)

\section{Key Words}

Diagnosis; Gastroesophageal reflux disease; Guideline; Meta-analysis; Treatment

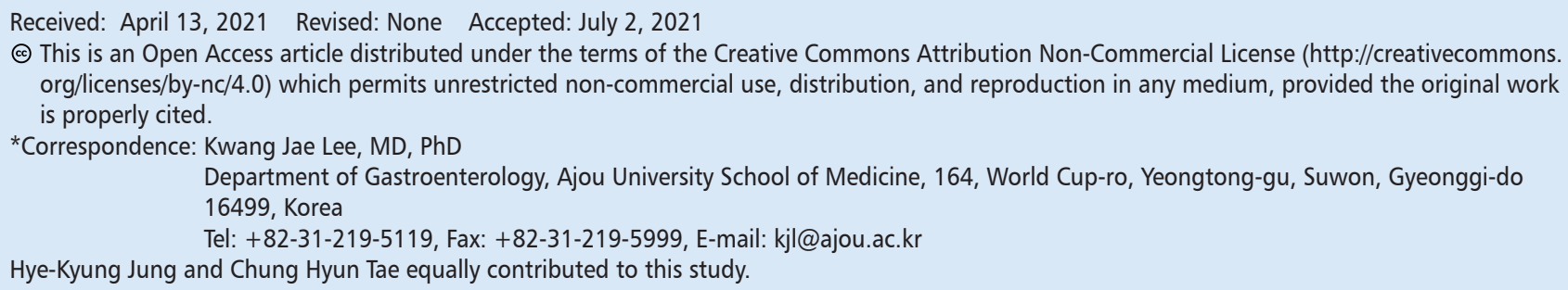

\section{Introduction}

Gastroesophageal reflux disease (GERD) is defined as a condition resulting when the stomach-content reflux causes troublesome symptoms and/or complications as per the Montreal global consensus. ${ }^{1}$ The prevalence of at least weekly experienced GERD symptoms reported in population-based studies worldwide is approximately $13 \%$, although there are significant geographical variations. ${ }^{2}$ Despite its high prevalence, the clinical disease characteristics and natural history are not fully elucidated. Categorizing GERD into 3 unique groups, non-erosive reflux disease (NERD), erosive reflux disease (ERD), and Barrett's esophagus, is the old model presenting GERD as a "spectrum" disease. ${ }^{3}$ This concept considered GERD as a single disease, potentially progressing from mild NERD toward metaplasia (Barrett's esophagus) and neoplasia (esophageal adenocarcinoma). Currently, GERD is used as an umbrella term with gastroesophageal reflux phenotypes associated with the incompetence of the esophagogastric junction (EGJ) and manifested by a hypotensive lower esophageal sphincter (LES), hiatal hernia, supine reflux, and poor acid clearance. ${ }^{4}$ The Rome IV criteria subdivided NERD into "true NERD," reflux hypersensitivity, and functional heartburn, based on the esophageal acid exposure and reflux symptom correlation from $\mathrm{pH}$ or 24-hour ambulatory $\mathrm{pH}$-impedance monitoring studies. ${ }^{5}$ The difference in symptom perceptions may be related to esophageal hypersensitivity or cognitive hypervigilance. Therefore, based on the GERD phenotypes and their pathophysiology, the diagnostic and therapeutic approaches should differ. However, the possible adverse effects from long-term use of proton pump inhibitors (PPIs) and the increase of unnecessary surgeries have been reported, and there is an argument that a more exact definition of GERD is needed. The Lyon consensus described "proven GERD" defining patients with GERD with objective physiological biomarkers. ${ }^{6}$

In patients with GERD, tailored treatment for GERD phenotypes effectively minimizes unnecessary treatment and finds optimal management, enabling efficient use of medical resources. However, it is necessary to evaluate whether the recent definitions of GERD can be accepted in Asia as well.

The 2020 Seoul Consensus on GERD Clinical Practice Guidelines present new evidence-based and expert-approved standards for the diagnosis and treatment of GERD in Asia.

\section{Methods}

These guidelines describe approaches to the practical management of adult patients with GERD based on scientific evidence and expert consensus. The guidelines cover several options for GERD treatment, summarizing their benefits and harms, and providing information on probable outcomes.

The present guidelines provide a practical, evidence-based guide for clinicians (gastroenterologists, surgeons, and general physicians), medical staff (including nurses, paramedical teams, medical students, and healthcare providers), patients, and the public.

The guideline steering committee consisted of the Presidents and key members of the Korean Society of Neurogastroenterology and Motility (KSNM) and the Asian Neurogastroenterology and Motility Association (ANMA). These clinical practical guidelines 
have been developed based on the methodology of the evidencebased medicine, and its specific method is similar to the one previously described. ${ }^{7}$

To develop these guidelines (started in May 2019), a professional with methodological expertise (Mi-Young Choi) conducted 4 workshops, and 11 meetings were held. The working group consisted of the Clinical Practical Guidelines Committee members and the GERD Committee, members recommended by ANMA and GERD experts. They conducted a literature search and metaanalysis addressing 3 directions: (1) definition and epidemiology, (2) diagnosis, and (3) treatment, and assigning 1 or 2 experts to each key question. The participating committee members provided a written consent on whether they had any conflicts of interest. The guideline development group members' competing interests are addressed in Supplementary Table 1.

A web survey using structured questionnaires, aimed at evaluating the patients' preferences and perspectives, was conducted in the largest internet community associated with GERD related to these guidelines. In November 2019, 8 structured GERD-related surveys were conducted for volunteers out of members internet community in 1 day. A total of 210 participants responded; $64.4 \%$ were adult women, $68.3 \%$ had ERD, and $14.6 \%$ had NERD. Among them, $57.6 \%$ of the respondents were willing to do chronic long-term maintenance, and $76.1 \%$ of them preferred on-demand therapy if needed. Their reasons for choosing the on-demand thera- py over the continuous therapy included fear of drug complications (66.3\%), poor drug compliance (5.4\%), cost (2.9\%), and difficulty to visit the hospital because of work $(2.0 \%)$. Therefore, we added a key question about on-demand therapy as maintenance therapy of GERD.

These guidelines were developed using de novo methods. To determine the clinical guidelines' scope, the working group members created key questions tailored to the population, intervention, control, and outcomes using nominal group techniques.

Working group members on each subject and Dr Mi-Young Choi of the National Evidence-based Healthcare Collaborating Agency selected the appropriate keywords. They conducted a literature search from July to September 2019 using the OvidMEDLINE, EMBASE, Cochrane Library, and KoreaMed databases. The keywords are listed in Supplementary Table 2. Two independent members reviewed the literature and selected the final studies following the set inclusion and exclusion criteria (Fig. 1).

The common inclusion criteria for studies' retrieval were: (1) adult human subjects or patients, (2) written in English or Korean, (3) systematic reviews and meta-analyses, randomized controlled trials (RCTs) or non-RCTs, (4) observational studies published between 2000 and 2019, and (5) studies with promising results reported. The common exclusion criteria were as follows: (1) studies on children or teenagers, (2) studies with not promising results re-

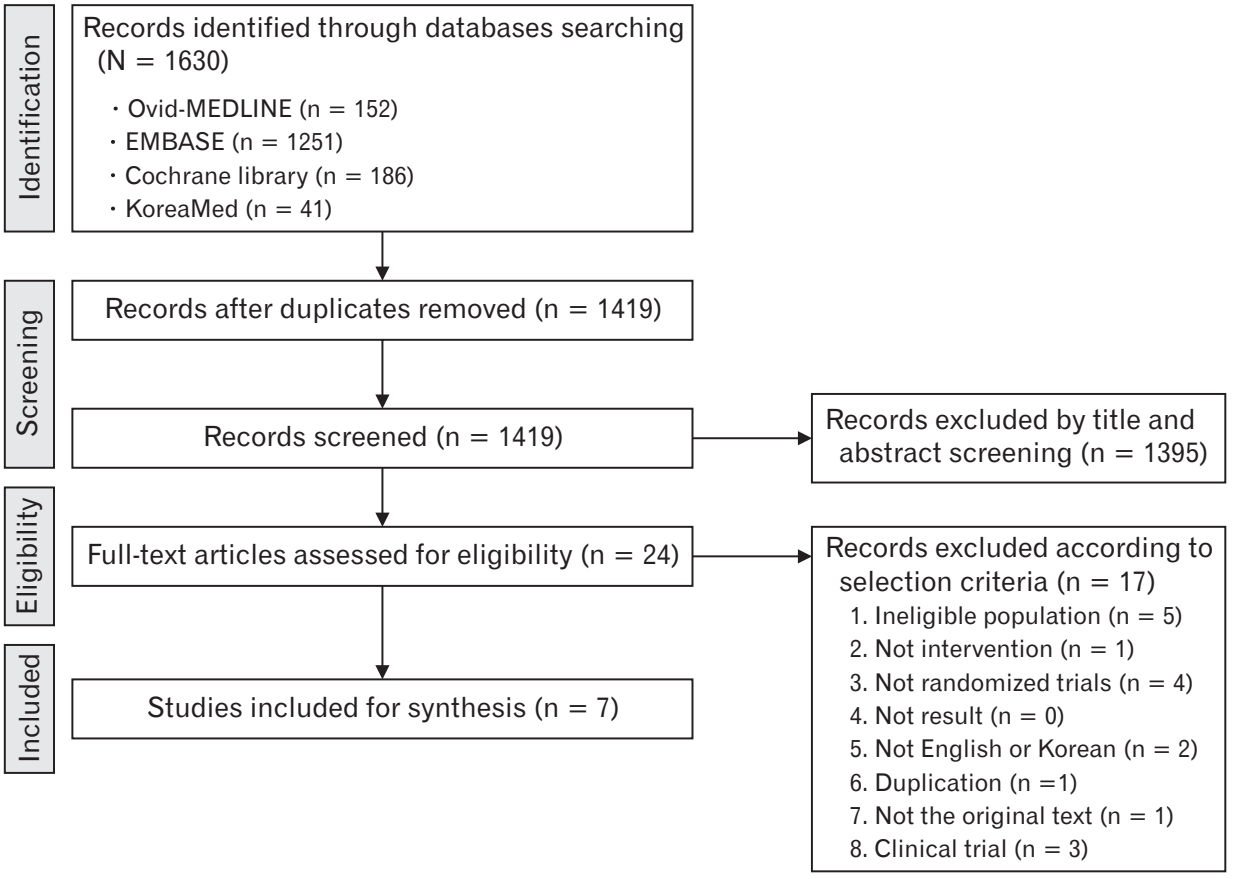

Figure 1. The Preferred Reporting Items for Systematic Reviews and Metaanalyses (PRISMA) flow diagram of the systematic review process of the efficacy of proton pump inhibitors in patients with non-cardiac chest pain. 
Table 1. Definition of Levels of Evidence and Strength of Recommendation

\begin{tabular}{|c|c|}
\hline \multicolumn{2}{|l|}{ Level of evidence } \\
\hline High & At least one RCT or SR/meta-analysis with no concern regarding study quality \\
\hline Moderate & $\begin{array}{l}\text { At least one RCT or SR/meta-analysis with minor concerns regarding study quality or, at least one cohort/case-control/ } \\
\text { diagnostic test design study with no concern regarding study quality }\end{array}$ \\
\hline Low & $\begin{array}{l}\text { At least one cohort/case-control/diagnostic test study with minor concerns regarding study quality, or at least one } \\
\text { single-arm before-after study or cross-sectional study with no concerns regarding study quality }\end{array}$ \\
\hline Very low & $\begin{array}{l}\text { At least one cohort/case-control/diagnostic test design study with serious concerns regarding study quality, or at least one } \\
\text { single-arm before-after study or cross-sectional study with minor/severe concerns regarding study quality }\end{array}$ \\
\hline \multicolumn{2}{|c|}{ Grade of recommendation } \\
\hline Strong for & $\begin{array}{l}\text { The benefits of the intervention are more significant than the harms based on a high or moderate level of evidence, such } \\
\text { that it can be strongly recommended for clinical practice in most cases }\end{array}$ \\
\hline Weak for & $\begin{array}{l}\text { The benefits and harms of the intervention may vary depending on the clinical situation or patients' characteristics. } \\
\text { Recommended depending on the clinical condition }\end{array}$ \\
\hline Weak against & $\begin{array}{l}\text { The benefits and harms of the intervention may vary depending on the clinical situation or patient characteristics. Inter- } \\
\text { vention is not recommended for clinical practice }\end{array}$ \\
\hline Strong against & $\begin{array}{l}\text { The intervention harms are greater than the benefits based on a high or moderate level of evidence. Intervention is not } \\
\text { recommended for clinical practice }\end{array}$ \\
\hline No recommendation & It is not possible to classify the recommendation due to a lack of evidence or equivocal results. Further evidence is needed \\
\hline
\end{tabular}

$\mathrm{RCT}$, randomized controlled trial; SR, systematic review.

ported, (3) unavailable to obtain original articles, and (4) case series or reports, expert opinion, narrative review, or guidelines.

Meta-analysis was conducted on possible key questions. Evidence profiles were created based on Grading of Recommendations, Assessment, Development, and Evaluation (GRADE) (Table 1). ${ }^{8}$ GRADEpro software was used to rank the quality of evidence according to 4 categories: high, moderate, low, and very low. The evidence quality assessment was then used to determine the supporting evidence strength informing a recommendation. ${ }^{9}$

Expert consensus was conducted using the modified Delphi method on the draft recommendations with evidence. An expert panel, consisting of KSNM and ANMA members and other experts, reviewed the draft. The first draft consisted of 25 recommendations with 1 open question: 7 on the GERD definition and epidemiology, 8 on diagnoses, and 10 pertaining to treatments. The first draft was sent via e-mail to the experts, and their responses were anonymized. A score of $>4$ on a 5 -point Likert scale was considered to correspond to "agree" (with the recommendation in question). If $>80 \%$ of all respondents agreed with a recommendation, a consensus was considered to have been reached. At the first round of e-mail voting, a consensus was not reached on only 4 of the 25 recommendations: on long-term complications of PPIs, use of PPIs in Barret's esophagus, prokinetics, and anti-reflux surgery. After the first round of appraisals, the working group presented the draft recommendations at an ANMA consensus meeting held on October 15, 2020. The second round of e-mail voting with modi- fied recommendations achieved consensus on anti-reflux surgery, but 3 recommendations were not agreed upon. These results are also described in Table 2.

Three external experts (Sanjiv Mahadeva [Malaysia], MyungGyu Choi [South Korea], and Shobna Bhatia [India] reviewed the recommendations in terms of necessity, appropriateness, healthcare setting, level of care, and balance between benefits and harms.

This guideline was presented in the academic symposium, 2020 Seoul Consensus on Clinical Practice Guidelines for GERD. It is uploaded on websites of the Korean Society of Neurogastroenterology and Motility (https:/www.ksgm.org) and the Korean Association of Internal Medicine (https://www.kaim.or.kr). Also, this guideline will be published in Korean.

This project was supported by the KSNM and a grant from the Patient-Centered Clinical Research Coordinating Center funded by the Ministry of Health \& Welfare, Republic of Korea (Grant No. HI19C0481 and HC19C0060). The GERD guidelines will be updated every 3 to 5 years to reflect the new evidence accumulated. 
Table 2. Summary of the Seoul Consensus on Gastroesophageal Reflux Disease

Level of Strength of

evidence recommendation

Definition and epidemiology

1 GERD is a condition characterized by regurgitation of gastric contents into the esophagus or the mouth, resulting in troublesome symptoms or complications

2 NERD is a subcategory of GERD. It is characterized by troublesome reflux symptoms with abnormally increased gastroesophageal reflux observed on 24-hour ambulatory $\mathrm{pH}$-impedance monitoring in the absence of esophageal mucosal injury confirmed on endoscopy

3 Reflux hypersensitivity is defined as retrosternal symptoms, including heartburn or chest pain triggered by physiological reflux in the absence of abnormally increased gastroesophageal reflux

4 Functional heartburn is defined as retrosternal burning discomfort or pain refractory to acid-suppressive therapy in the absence of GERD

5 Refractory GERD is defined as GERD symptoms unresponsive to the administration of $\geq 8$ weeks of a standard dose of an acid-suppressive agent

6 GERD can cause various extra-esophageal symptoms such as cough, asthma, hoarseness, or non-cardiac chest pain. Extra-esophageal GERD symptoms may or may not be accompanied by typical GERD symptoms

7 The prevalence of GERD is increasing in Asian countries

Diagnosis of GERD

8 Symptom-based diagnostic questionnaires are useful for the accurate diagnosis of GERD

9 A 2-week trial of a standard dose of PPI should be recommended as a sensitive and practical test for GERD diagnosis in patients with typical GERD symptoms

10 Endoscopy with or without biopsy can be recommended to diagnose GERD and exclude other organic diseases

11 Endoscopic surveillance is recommended in patients with long-segment Barrett's esophagus

12 Twenty-four-hour ambulatory $\mathrm{pH}$-impedance monitoring is indicated in patients with GERD symptoms that are refractory to PPI therapy. This test is also recommended before anti-reflux surgery

13 A value of the total esophageal acid exposure time of $\geq 4 \%$ is defined as an abnormal finding in Asian adults

14 Esophageal manometry is useful in the assessment of peristaltic function and exclusion of alternative motility disorders. Therefore, esophageal manometry should be performed before anti-reflux surgery in patients with GERD

15 Novel impedance parameters, including baseline impedance and post-reflux swallow-induced peristaltic wave, are promising in the GERD diagnosis and increase GERD diagnostic yield

Treatment of GERD

16 Weight reduction is recommended to improve GERD symptoms in overweight patients or those diagnosed with obesity

17 The administration of a standard dose of PPI once a day for 4 to 8 weeks is recommended as the initial treatment of GERD

18 Double-dose PPI therapy may be effective in patients with GERD who do not show an adequate response to standard-dose PPI therapy

19 On-demand PPI therapy's effectiveness is comparable with that of continuous daily PPI therapy for the long-term management of patients with NERD or mild erosive reflux disease

20 PPI therapy is recommended to treat NCCP in patients who present with concomitant typical GERD symptoms

21 The effect of P-CABs is comparable with that of PPIs for the initial treatment of patients with GERD

22 Anti-reflux surgery can be recommended as an alternative to PPI maintenance therapy to improve symptoms and quality of life in patients with proven GERD
NA

NA

NA

NA

NA

NA

NA

NA

NA

NA

NA

NA

Moderate

NA

Low

Weak

Moderate

Strong

Very low

Strong

Very low

Strong

Very low

Strong

Moderate

Weak

Low

Strong

Low

Weak

Moderate

Strong

High

Strong

Moderate

Weak

Moderate

Weak

Moderate

Strong

Moderate Strong

Moderate Weak

GERD, gastroesophageal reflux disease; NERD, non-erosive reflux disease; PPI, proton pump inhibitor; NCCP, non-cardiac chest pain; P-CABs, potassiumcompetitive acid blockers; NA, not applicable. 


\section{Definition and Epidemiology}

\section{Definition}

\section{Definition of gastroesophageal reflux disease}

Statement 1: Gastrointestinal reflux disease is a condi-
tion characterized by regurgitation of gastric contents
into the esophagus or the mouth, resulting in trouble-
some symptoms or complications.
$\quad$ Level of evidence: not applicable (NA)
$\quad$ Strength of recommendation: NA
$\quad$ Experts' opinions: agree strongly $(91.1 \%)$, agree with some
reservations $(8.9 \%)$, undecided $(0.0 \%)$, disagree $(0.0 \%)$, and dis-
agree strongly $(0.0 \%)$

GERD is a common disorder of the upper gastrointestinal tract, adversely impacts health-related quality of life (HRQOL), and increases medical costs. GERD is defined as a condition in which gastric contents regurgitate into the esophagus or beyond, resulting in either troublesome symptoms or complications. The definition of GERD has been similarly adopted in most practice guidelines since the Montreal definition in 2006. This definition is also similar to the Montreal definition. Symptoms related to GERD become troublesome when they adversely affect an individual's wellbeing. Generally, a symptom is considered troublesome when mild symptoms occurred for $\geq 2$ or more days a week, or moderate/ severe symptoms occurred $>1$ day per week as per a populationbased study.

\section{Definition of non-erosive reflux disease}

Statement 2: Non-erosive reflux disease is a subcategory of gastroesophageal reflux disease. It is characterized by troublesome reflux symptoms with abnormally increased gastroesophageal reflux observed on 24-hour ambulatory $\mathrm{pH}$-impedance monitoring in the absence of esophageal mucosal injury confirmed on endoscopy.

Level of evidence: NA

Strength of recommendation: NA

Experts' opinions: agree strongly (75.6\%), agree with some reservations $(22.2 \%)$, undecided $(2.2 \%)$, disagree $(0.0 \%)$, and disagree strongly $(0.0 \%)$
GERD is classified into NERD without mucosal breaks on endoscopic examination in the presence of symptoms and ERD with mucosal breaks. The severity of reflux esophagitis is usually classified following the Los Angeles (LA) classification (from A to $\mathrm{D}$, denoting increasing inflammation severity and extension). Minimal changes of the lower esophageal mucosa are not considered mucosal breaks. Most patients (about 70\%) with typical reflux symptoms have no evidence of erosive esophagitis (EE) at endoscopy. ${ }^{10,11}$ These patients are usually considered to have NERD, particularly if there is supportive evidence that their symptoms are related to abnormally increased acid exposure based on $\mathrm{pH}$ or 24hour ambulatory $\mathrm{pH}$-impedance monitoring. Therefore, recent studies showed NERD represents a group of patients with several pathophysiological and clinical differences and should be better classified using 24-hour ambulatory $\mathrm{pH}$-impedance monitoring. ${ }^{12,13}$

\section{Definition of reflux hypersensitivity}

Statement 3: Reflux hypersensitivity is defined as retrosternal symptoms, including heartburn or chest pain triggered by physiological reflux in the absence of abnormally increased gastroesophageal reflux.

Level of evidence: NA

Strength of recommendation: NA

Experts' opinions: agree strongly (62.2\%), agree with some reservations $(35.6 \%)$, undecided $(2.2 \%)$, disagree $(0.0 \%)$, and disagree strongly $(0.0 \%)$

Reflux hypersensitivity is a new functional esophageal disorder introduced by the Rome IV criteria. ${ }^{5}$ Based on those criteria, reflux hypersensitivity is defined as retrosternal symptoms including heartburn or chest pain triggered with reflux events despite normal acid exposure on $\mathrm{pH}$ or 24-hour ambulatory $\mathrm{pH}$-impedance monitoring (response to anti-secretory therapy does not exclude diagnosis). There should be no structural changes, eosinophilic esophagitis, and major motility disorders (achalasia, EGJ outflow obstruction, distal esophageal spasm, Jackhammer esophagus, and absent contractility) explaining the symptoms in this diagnosis. Criteria must be fulfilled for the past 3 months with symptom onset at least 6 months before diagnosis with a frequency of at least twice a week. ${ }^{14}$ Based on the Rome IV criteria, reflux hypersensitivity is differentiated from functional heartburn or even NERD by its greater associations of reflux symptoms. However, recent data suggest the need for a return to including reflux hypersensitivity in the GERD spectrum. Alterations in esophageal mucosal integrity and chemical clearance, microscopic esophagitis, and strict symptom-reflux asso- 
ciation of reflux hypersensitivity support that reflux hypersensitivity should be considered as GERD. ${ }^{15}$

\section{Definition of functional heartburn}

Statement 4: Functional heartburn is defined as
retrosternal burning discomfort or pain refractory
to acid-suppressive therapy in the absence of gastro-
esophageal reflux disease.
$\quad$ Level of evidence: NA
Strength of recommendation: NA
$\quad$ Experts' opinions: agree strongly $(46.7 \%)$, agree with some
reservations $(37.8 \%)$, undecided $(13.3 \%)$, disagree $(2.2 \%)$, and
disagree strongly $(0.0 \%)$

The definition of functional heartburn includes burning retrosternal discomfort or pain in patients without symptom relief despite optimal anti-secretory therapy in the absence of GERD on 24-hour ambulatory $\mathrm{pH}$-impedance monitoring. There should be no structural changes, eosinophilic esophagitis, and major motility disorders that can explain heartburn. Criteria must be fulfilled for the past 3 months with symptom onset at least 6 months before diagnosis with a frequency of at least twice a week.

\section{Definition of refractory gastroesophageal reflux disease}

Statement 5: Refractory gastroesophageal reflux disease is defined as gastroesophageal reflux disease symptoms unresponsive to the administration of $\geq 8$ weeks of a standard dose of an acid-suppressive agent.

Level of evidence: NA

Strength of recommendation: NA

Experts' opinions: agree strongly (37.8\%), agree with some reservations $(57.8 \%)$, undecided $(4.4 \%)$, disagree $(0.0 \%)$, and disagree strongly $(0.0 \%)$

There is currently no established consensus regarding the definition of refractory GERD in terms of a treatment regimen, symptom frequency, and degree of treatment response. Some investigators consider a poor response to once-daily PPI as refractory, while others consider partial or lack of response to PPI therapy twice daily as refractory symptoms. In addition to the PPI dose, the duration of acid-suppressive treatment required to define refractoriness varies from 4 weeks to 12 weeks. ${ }^{16-19}$ In Asia, it may be reasonable to use the term refractory GERD for patients whose symptoms fail to respond partially or entirely to $\geq 8$ weeks of a standard dose of the acid-suppressive agent.
The prevalence of refractory GERD is reported with variations following the definition of refractoriness and study population. It has been estimated that up to $40.0 \%$ of patients with GERD remain symptomatic while on PPI therapy. ${ }^{20-23}$ Systematic review of observational studies in primary care or community-based studies showed that $45.0 \%$ of patients reported persistent reflux symptoms. ${ }^{24}$ The prevalence of persistently troublesome heartburn and regurgitation in interventional trials were $17.0 \%$ and $28.0 \%$ in nonRCTs, and $32.0 \%$ and $28.0 \%$ in RCTs, respectively. ${ }^{24}$

It has been suggested that the proportion of patients who fail to get PPI therapy relief is higher in NERD than in $\mathrm{EE}{ }^{25-28}$ In a previous Korean study, $19.5 \%$ of patients with NERD and $10.2 \%$ of patients with EE had refractory symptoms after 8 weeks of PPI therapy. ${ }^{26}$ Japanese studies also have shown that reflux symptoms are 20.0-25.0\% less likely to respond to PPI treatment in patients with NERD than in patients with EE. ${ }^{27,28}$

Extra-esophageal symptoms of gastroesophageal reflux disease

Statement 6: Gastroesophageal reflux disease can cause various extra-esophageal symptoms such as cough, asthma, hoarseness, or non-cardiac chest pain. Extra-esophageal gastroesophageal reflux disease symptoms may or may not be accompanied by typical gastroesophageal reflux disease symptoms.

Level of evidence: NA

Strength of recommendation: NA

Experts' opinions: agree strongly $(62.2 \%)$, agree with some reservations $(35.6 \%)$, undecided $(2.2 \%)$, disagree $(0.0 \%)$, and disagree strongly $(0.0 \%)$

GERD causes not only typical symptoms but also respiratory or laryngeal symptoms called extra-esophageal symptoms. Previous studies have reported chronic cough, hoarseness, asthma, globus sensation, sleep disturbance, and dental erosion as extraesophageal symptoms of GERD (Table 3). ${ }^{17,29-31}$

Among these symptoms, cough, asthma, hoarseness, and noncardiac chest pain (NCCP) are more commonly associated with GERD. There have been various investigations about the prevalence, possible pathophysiology, and symptom response to PPIs administration in empirical trials between GERD and extra-esophageal symptoms. GERD has been considered to be one of the most common causes of chronic cough. ${ }^{32}$ Reflux above the upper esophageal sphincter could lead to cough as a protective mechanism. Moreover, a cough could vice versa lead to reflux. ${ }^{32}$ Also, patients 
Table 3. Possible Extra-esophageal Symptoms of Gastroesophageal Reflux Disease

Laryngopharyngeal symptoms
Chronic throat clearing
Globus
Hoarseness
Dysphonia
Respiratory symptoms
Cough
Pulmonary fibrosis
Lung transplant rejection
Asthma
Others
Dental erosion
Otitis
Sinusitis
Postnasal drip

with GERD are 1.15 times more likely to have asthma than those without GERD. ${ }^{33}$ In terms of pathophysiology, reflux might induce asthma either directly or indirectly. Reflux in GERD might directly impact the airway through micro-aspiration, resulting in asthma. Acid reflux also might induce a bronchial spasm enhanced by a vagus-medicated mechanism. ${ }^{34}$ Hoarseness, as well as a lump-inthe-throat sensation, are common symptoms of laryngopharyngeal reflux, affecting the vocal cords and surrounding tissues. ${ }^{35}$ After the cardiac source of chest pain has been excluded, NCCP is defined as recurrent angina-like or substernal chest pain. ${ }^{36}$ GERD is the most common esophageal cause for $\mathrm{NCCP}^{37}$ In a retrospective nationwide study of 904 subjects with normal coronary angiogram and upper endoscopy within 2 years, GERD was present in $48.2 \%$ of the NCCP patients. ${ }^{38}$

The prevalence of extra-esophageal symptoms varies widely depending on the study subject and the symptoms' definition. The prevalence of extra-esophageal symptoms was $80.0 \%$ in patients complaining of typical symptoms more than once a week in a population-based study in Minnesota. ${ }^{39}$ In open cohort studies in Europe, extra-esophageal symptoms were identified in $32.8 \%$ of patients with GERD and were reported higher than in patients with NERD (30.9\%) and lower than those with ERD (34.5\%). ${ }^{39}$ To date, epidemiologic data on the extra-esophageal symptom in Asia are limited. In a study conducted in Korea, the prevalence of extra-esophageal symptoms, including globus, chest pain, cough, hoarseness, and wheezing, was $74.4 \%$. $^{40}$ The most prevalent extraesophageal symptom was globus, followed by chest pain, cough, hoarseness, and wheezing. ${ }^{40}$

\section{Epidemiology of Gastroesophageal Reflux Disease}

\author{
Statement 7: The prevalence of gastroesophageal re- \\ flux disease is increasing in Asian countries. \\ Level of evidence: moderate \\ Strength of recommendation: NA \\ Experts' opinions: agree strongly (68.9\%), agree with some \\ reservations $(31.1 \%)$, undecided $(0.0 \%)$, disagree $(0.0 \%)$, and \\ disagree strongly $(0.0 \%)$
}

Epidemiologic studies have reported an increasing trend of GERD, especially in Asia. ${ }^{41}$ In population-based studies, the prevalence of symptom-based GERD was reported to increase in Eastern Asia (2.5-4.8\% before 2005 and 5.2-8.5\% in 2005-2010). In Southeast and Western Asia, the prevalence of GERD was higher than in Eastern Asia. The prevalence of EE had increased in subjects receiving a medical check-up in Eastern Asia. Nationwide multi-center cross-sectional study review of endoscopic findings in Korea reported that the prevalence of $\mathrm{EE}$ had risen steadily from $1.8 \%$ in 1995 to $5.9 \%$ in 2000 , and $9.1 \%$ in $2005 .^{42}$ In a retrospective review of GERD endoscopic diagnoses in the Chinese population over time, the prevalence of $\mathrm{EE}$ had increased in the referral populations from $20.7 \%$ to $51.0 \%$ and by screening endoscopy from $14.5 \%$ to $23.5 \%{ }^{43}$ In a cohort study using a validated GERD questionnaire (GerdQ) in Singapore, there is a rising trend of reflux-symptoms incidence in the general population over 5 years. ${ }^{44}$ A study conducted in Taiwan reported that the crude prevalence of esophagitis increased from $5.0 \%$ in 1995 to $12.6 \%$ in $2002 .{ }^{45}$

We performed meta-analyses including 37 population-based studies in the general population and 36 observational studies (21 cross-sectional, 12 cohort, and 3 case-control studies) in subjects who underwent a medical check-up from January 2000 to October 2019 in Asia (Supplementary Fig. 1). We compared the prevalence of GERD in both 2000-2009 and 2010-2019 in each study. The significant subgroup effect of the test was considered to be $P<0.1$. In the population-based study, GERD's prevalence significantly increased from 2000-2009 to 2010-2019 (11.0\% vs $15.0 \%$, respectively, $P=0.092$ ) (Supplementary Fig. 2). However, heterogeneity among studies in each group was considerable. In the observational study of subjects who underwent the medical check-up, GERD's prevalence significantly increased from 2000-2009 to 2010-2019 (6.0\% vs $15.0 \%$, respectively, $P=0.000$ ) (Supplementary Fig. 3). NERD and ERD prevalence also increased significantly from 2000-2009 and 2010-2019 (4.0\% vs $8.0 \%$, respectively, $P=0.012$; $7.0 \%$ vs $10.0 \%$, respectively, $P=0.074$ ) (Supplementary Fig. 4 
and 5 , respectively). Heterogeneity among studies in each group was also considerable and significant. Overall, the prevalence of GERD is increasing in Asian countries.

\section{Diagnosis}

\section{Symptom-based Diagnostic Questionnaires}

Statement 8: Symptom-based diagnostic question-
naires are useful for the accurate diagnosis of gastro-
esophageal reflux disease.
Level of evidence: low
Strength of recommendation: weak
Experts' opinions: agree strongly $(20.0 \%)$, agree with some
reservations $(66.7 \%)$, undecided $(8.9 \%)$, disagree $(4.4 \%)$, and
disagree strongly $(0.0 \%)$

Several types of questionnaires have been developed to assess GERD to date. ${ }^{46}$ These tools can be used to determine generic gastrointestinal symptoms, esophageal or extra-esophageal symptoms, burden on the quality of life and response to treatment, and create symptoms profiles. On the other hand, one of the most valuable clinical benefits of the questionnaire is that it can increase the accuracy of diagnosis. A structural questionnaire is used to identify patients who may be the appropriate choice to administer antisecretory drugs, thus improving the quality of diagnosis to a level reached by experienced physicians or diagnosing GERD at a level close to the physiologic test results. Several questionnaires had been validated and used for diagnostic purposes. The GerdQ and Reflux Disease Questionnaire (RDQ) are the most frequently used questionnaires with multilingual versions. ${ }^{46-48}$ The GerdQ use confirmed that a family practitioner could diagnose GERD at a gastroenterologist level. ${ }^{47}$ Moreover, about $80.0 \%$ of the subjects with $\geq 8$ points filled a positive result of one diagnostic modality including $\mathrm{pH}$-study, endoscopy, or positive response to PPI treatment. GerdQ and RDQ are both modestly accurate for GERD's symptom-based diagnosis but have limitations as a stand-alone diagnostic tool. ${ }^{49}$ Recently, one GERD-related questionnaire, a Self-evaluation Questionnaire for GERD (SEQ-GERD), has been developed in Korea and has been validated internally and externally. The SEQGERD can also monitor the responsiveness of medical treatment in GERD. In primary care settings, structural questionnaires such as GerdQ, RDQ, or SEQ-GERD can guarantee a certain medical quality level. They can be helpful in conjunction with PPI test.

\section{Proton Pump Inhibitor Test}

Statement 9: A 2-week trial of a standard dose of
proton pump inhibitor should be recommended as a
sensitive and practical test for gastroesophageal reflux
disease diagnosis in patients with typical gastroesopha-
geal reflux disease symptoms.
$\quad$ Level of evidence: moderate
$\quad$ Strength of recommendation: strong
$\quad$ Experts' opinions: agree strongly ( $35.6 \%)$, agree with some
reservations $(60.0 \%)$, undecided ( $4.4 \%)$, disagree $(0.0 \%)$, and
disagree strongly $(0.0 \%)$

Heartburn and acid regurgitation are the cardinal symptoms of GERD. Symptoms may be used to diagnose GERD with reported sensitivity and specificity of $62.0 \%$ and $67.0 \%$, respectively. ${ }^{50} \mathrm{PPI}$ test may be started without further investigation in patients who present with typical symptoms of GERD. Improvement in symptoms after PPI test has a sensitivity of $71.0 \%$ and specificity of only $44.0 \%{ }^{16}$

We performed a systematic review of 17 studies investigating the diagnostic performance of empirical PPIs for GERD (Supplementary Fig. 6). A meta-analysis of 17 studies revealed that sensitivity and specificity of the PPI test were 0.78 (95\% confidence interval $[\mathrm{CI}], 0.71-0.84)$ and 0.40 (95\% CI, 0.31-0.48), respectively (Supplementary Fig. 7). We also performed subgroup analysis for dose (single vs double) and duration ( $<2$ weeks vs $>2$ weeks) of PPIs, and they did not affect sensitivity and specificity (Supplementary Fig. 8). In another recent network meta-analysis, PPI test had high sensitivity and the lowest specificity among several diagnostic tests, including 24-hour ambulatory $\mathrm{pH}$-impedance monitoring and GerdQ. ${ }^{51}$

PPI test has some limitations. The response rates are much lower with atypical symptoms such as chest pain, chronic cough, and laryngitis. ${ }^{52}$ Patients with reflux hypersensitivity may also respond to PPI trials, thus leading to over-diagnosis of GERD. ${ }^{53,54}$ Despite these limitations, specialized investigations such as 24-hour ambulatory $\mathrm{pH}$-impedance monitoring is not widely available nor cost-effective. Therefore, a therapeutic PPI test may have pragmatically diagnostic value in patients with typical GERD symptoms. 


\section{Endoscopy}

Statement 10: Endoscopy with or without biopsy can
be recommended to diagnose gastroesophageal reflux
disease and exclude other organic diseases.
Level of evidence: very low
Strength of recommendation: strong
$\quad$ Experts' opinions: agree strongly $(53.3 \%)$, agree with some
reservations $(42.2 \%)$, undecided $(2.2 \%)$, disagree $(2.2 \%)$, and
disagree strongly $(0.0 \%)$

Endoscopy has long been the primary tool used to evaluate the esophageal mucosal injury in patients with GERD symptoms. However, endoscopy is not required in the presence of typical GERD symptoms according to recent guidelines. ${ }^{30}$ In patients with GERD symptoms who do not respond to a PPIs trial, the upper endoscopy is recommended to evaluate GERD and diagnose the organic disease in the esophagus. Sometimes, endoscopy is recommended before PPI treatment because it is challenging to distinguish between ERD and NERD after treatment. ${ }^{18}$

The LA classification has been used to assess the mucosal injury; however, symptoms and endoscopic findings are not always correlated. $^{55,56}$ The intensity and frequency of reflux symptoms are poor predictors of the presence of severe reflux esophagitis.

Previous studies have shown that only one-third of patients with endoscopic LA grade A report had GERD symptoms. ${ }^{10}$ The endoscopic findings of LA grade B had a significant inter-observer variability. Therefore, endoscopic LA grades C or D esophagitis, Barrett's esophagus, or peptic stricture are considered the confirmatory evidence for GERD in the Lyon consensus. ${ }^{6,57}$ However, the prevalence of endoscopic EE was reported to be $6.7 \%$ of the Korean population. Among them, only $1.0 \%$ was diagnosed as LA grade C or D. ${ }^{58}$ Furthermore, many gastrointestinal experts consider LA grade $\mathrm{B}$ as a definitive GERD needing treatment. Therefore, studies of the natural history and outcome of therapy based on GERD's endoscopic findings are required.

Endoscopy with biopsy is the most accurate tool for diagnosing organic diseases, including EE, peptic strictures, esophageal malignancy, Barrett's esophagus, and other esophageal disorders such as eosinophilic esophagitis (EoE). Esophageal cancer is the sixth most common cause of cancer-related deaths, with a 5-year survival rate of $<20.0 \%$ despite advances in treatment. Therefore, endoscopy is recommended in the presence of alarm symptoms such as dysphagia, unintentional weight loss, and hematemesis and patients at high risk for esophageal malignancy. ${ }^{59}$ Endoscopy with biopsies has been useful for the diagnosis of EoE. A prevalence rate of approximately $0.5 \%$ per endoscopy was reported, and the prevalence of EoE had increased significantly during the study period. ${ }^{60}$ In Korea, a previous study also showed EoE in about 40 cases in 1000 biopsies specimens, with the incidence gradually increasing. ${ }^{61}$ When patients are referred for an upper endoscopy due to dysphagia, a diagnosis of EoE can be made in 10.0-15.0\% of the cases, with $11.0 \%$ due to food impactions. So, a biopsy is recommended for patients with reflux esophagitis who complain of dysphagia or food impactions. ${ }^{62,63}$

Endoscopy with biopsies could be useful in the differential diagnosis of NERD, reflux hypersensitivity, and functional heartburn. Structured histopathological findings of reflux esophagitis are included papillary elongation, basal cell hyperplasia, dilated intercellular spaces, intraepithelial inflammatory cells, necrosis, and erosions. ${ }^{64}$ Because these histopathological findings are neither sensitive nor specific for the diagnosis of GERD, routine biopsies in the esophagus are not recommended for the diagnosis of GERD.

\section{Endoscopic Surveillance for Barrett's Esophagus}

Statement 11: Endoscopic surveillance is recommend-
ed in patients with long-segment Barrett's esophagus.
Level of evidence: very low
Strength of recommendation: strong
Experts' opinions: agree strongly (40.0\%), agree with some
reservations (48.9\%), undecided (6.7\%), disagree (4.4\%), and
disagree strongly $(0.0 \%)$

Although the impact of endoscopic surveillance for Barrett's esophagus has not been thoroughly evaluated, Western guidelines recommend periodic endoscopic surveillance in patients with Barrett's esophagus. ${ }^{30,65}$ The primary purpose of surveillance endoscopy in patients with Barrett's esophagus is to reduce mortality. A recent meta-analysis, including 1 case-control study and 4 cohort studies, has compared mortality between patients with Barret's esophagus under endoscopic surveillance and those who were not. ${ }^{66-71}$ This meta-analysis showed that endoscopic surveillance had a benefit in terms of esophageal adenocarcinoma-related mortality as well as all-cause mortality. The pooled risk ratio (RR) of surveillance in esophageal adenocarcinoma-related mortality was 0.60 (95\% CI, 0.50-0.71). Additionally, the pooled hazard ratio (HR) of surveillance in all-cause mortality was 0.75 (95\% CI, 0.59-0.94).

The beneficial effect of surveillance endoscopy is due to the early diagnosis and treatment of adenocarcinoma. In the meta-analysis, it has been shown that patients who had undergone surveillance endoscopy were diagnosed with esophageal adenocarcinoma at an 
early stage compared to those who had not undergone surveillance endoscopy (pooled RR for early diagnosis, 2.11; 95\% CI, 1.084.11). ${ }^{66}$ Conversely, the risk of surgical treatment was higher in patients who had undergone surveillance endoscopy than in those who had not undergone surveillance endoscopy (pooled RR for surgical treatment, 1.47; 95\% CI, 0.92-2.33).

However, there is still controversy whether all patients with Barrett's esophagus should be recommended for surveillance endoscopy. The Asian-Pacific consensus on the management of GERD published in 2016 stated that, at present, there is no proven benefit in endoscopic surveillance of Barrett's esophagus in the absence of dysplasia. ${ }^{17}$ Recently, however, an interesting meta-analysis evaluated the progression of non-dysplastic Barrett's esophagus. ${ }^{72}$ In this meta-analysis, the annual rates of progression to esophageal adenocarcinoma were $0.06 \%$ (95\% CI, 0.01-0.10) in the shortsegment Barrett's esophagus and $0.31 \%$ (95\% CI, 0.21-0.40) in the long-segment Barrett's esophagus. The risk of progression to esophageal adenocarcinoma was higher in the long-segment Barrett's esophagus than in the short-segment Barrett's esophagus (pooled odds ratio [OR], 0.25; 95\% CI, 0.11-0.56). ${ }^{72}$ Therefore, surveillance endoscopy may be recommended in patients with longsegment Barrett's esophagus rather than short-segment Barrett's esophagus. The impact of surveillance endoscopy in patients with short-segment Barrett's esophagus should be further investigated.

Besides, the interval of endoscopic surveillance is another issue. Although there is a lack of evidence in establishing the optimal endoscopic surveillance interval, it was performed every 2 or 3 years in most previous studies. ${ }^{67,69-71}$ It is still too early to determine the

Table 4. Possible Causes of Refractory Gastroesophageal Reflux Symptoms

Non-GERD
Functional heartburn
Functional dyspepsia
Esophageal motility disorder (eg, achalasia)
Eosinophilic esophagitis
Insufficient acid suppression
Lack of compliance
Improper dosing time
Reduced bioavailability of PPIs
Hypersecretory state (eg, Zollinger-Ellison syndrome)
Weakly acidic or non-acidic reflux
Concomitant functional disorder or psychological comorbidity
Delayed gastric emptying
Reflux hypersensitivity

GERD, gastroesophageal reflux disease; PPIs, proton pump inhibitors. optimal surveillance interval in patients with Barrett's esophagus. However, at present, 2 or 3 years of endoscopy may be considered for early diagnosis of esophageal adenocarcinoma in patients with Barrett's esophagus, especially in those with long-segment Barrett's esophagus.

\section{Twenty-four-hour Ambulatory pH-impedance Monitoring for Gastroesophageal Reflux Disease}

Statement 12: Twenty-four-hour ambulatory pH-
impedance monitoring is indicated in patients with
gastroesophageal reflux disease symptoms refractory
to proton pump inhibitor therapy. This test is also rec-
ommended before anti-reflux surgery.
Level of evidence: very low
Strength of recommendation: strong
Experts' opinions: agree strongly $(73.3 \%)$, agree with some
reservations $(24.4 \%)$, undecided $(2.2 \%)$, disagree $(0.0 \%)$, and
disagree strongly $(0.0 \%)$

Various mechanisms for intractable GERD symptoms have been suggested, including incorrect diagnosis, insufficient acid suppression, weakly acidic or non-acidic reflux, and the presence of concomitant functional disorder (Table 4). GERD's diagnosis often relies on subjective evaluation of symptoms without an objective measure of pathological reflux. However, reflux symptoms that are not necessarily arising from GERD, and symptoms arising from an esophageal motility disorder could be misinterpreted as reflux symptoms. Therefore, presenting symptoms should be thoroughly reassessed, and a possible alternative diagnosis should be considered, particularly when the diagnosis of GERD was made solely based on symptoms. ${ }^{73,74}$ Other important factors contributing to treatment failure are poor compliance and inadequate dosing. ${ }^{75}$ Previous studies revealed that only $26.0 \%$ of the patients with reflux symptoms were dosed optimally, and $29.6 \%$ of patients who were dosed sub-optimally consumed their PPIs after meals. ${ }^{76}$ Therefore, compliance and dosing should be optimized to improve treatment response.

The first investigation in patients with refractory symptoms is upper endoscopy to exclude non-reflux esophageal disorders such as EoE and achalasia. ${ }^{17,30}$ Otherwise, further evaluation with 24hour ambulatory $\mathrm{pH}$-impedance monitoring and/or esophageal manometry is recommended to determine the underlying pathophysiology. Whether reflux monitoring should be performed after stopping PPIs or while on medication may be chosen based on GERD's pretest likelihood. ${ }^{77,78}$ Patients can be tested "off" therapy 
to rule out GERD or “on” treatment using 24-hour ambulatory $\mathrm{pH}$-impedance monitoring to determine if reflux is associated with the persisting symptom. ${ }^{30}$

Combined 24-hour ambulatory $\mathrm{pH}$-impedance monitoring enabled comprehensive evaluation of both physical and chemical properties of the refluxate. It allows characterization of the reflux episode, including weakly acidic or non-acidic reflux, and facilitates differentiation between patients with NERD and those with reflux hypersensitivity or functional heartburn. ${ }^{53,79-81}$ In a previous study, $39.8 \%$ of symptoms were associated with non-acid reflux in NERD patients with persistent symptoms despite at least twice daily PPI therapy. ${ }^{82}$ Another study showed no identifiable relationship between acid or non-acid reflux episodes and reflux symptoms in more than half of patients refractory to at least daily PPI therapy. ${ }^{83}$

\section{The Value of Abnormal Esophageal Acid Exposure Time}

Statement 13: A value of total esophageal acid expo-
sure time of $\geq 4 \%$ is defined as an abnormal finding
in Asian adults.
$\quad$ Level of evidence: moderate
$\quad$ Strength of recommendation: weak
$\quad$ Experts' opinions: agree strongly $(20.0 \%)$, agree with some
reservations ( $68.9 \%)$, undecided $(11.1 \%)$, disagree $(0.0 \%)$, and
disagree strongly $(0.0 \%)$

Twenty-four-hour ambulatory $\mathrm{pH}$-impedance monitoring is usually considered when there is a need for a definite diagnosis of GERD. ${ }^{6,84}$ It can be used to detect and characterize reflux and its symptom association. Reflux monitoring reveals GERD's pathophysiology as either excessive esophageal acid exposure time (AET) or reflux episodes. Among the $\mathrm{pH}$ monitoring metrics, esophageal AET is the most reproducible parameter reliably extracted from automated analysis. ${ }^{85}$ It is predictive of response from medical and surgical reflux therapy. ${ }^{86,87}$ In distinguishing endoscopically proven esophagitis patients from normal control subjects, AET values have shown $77-100 \%$ sensitivity and $85-100 \%$ specificity in the previous studies. $^{88}$

The Porto consensus suggests that esophageal acid exposure is considered pathological if AET $>6 \%$ on $\mathrm{pH}$ testing as new concepts of areas of uncertain diagnosis appear (LA classification grade $\mathrm{A}$ and $\mathrm{B}$ and AET between 4-6\%). ${ }^{84}$ Lyon consensus proposes that $\mathrm{AET}<4 \%$ is considered normal (physiological), and $>6 \%$ is deemed abnormal and presents the concept of inconclusive with intermediate values between these limits. ${ }^{6}$
To determine the range of normal values for Asians, a metaanalysis was performed based on the AET (\%) of asymptomatic subjects presented in 19 Asian studies (Supplementary Table 3). ${ }^{89-}$ ${ }^{107}$ As a result of the analysis, the upper normal limit of AET calculated through meta-analysis was $3.2 \%$ (95\% CI, 2.70-3.90\%) (Supplementary Fig. 9). Therefore, we propose that more than $4.0 \%$ of AET be judged as abnormally high in Asians. However, while this is a reasonable threshold for determining the abnormal range, it may not be the threshold for inducing GERD symptoms.

Compared to $\mathrm{pH}$-based reflux monitoring alone, 24-hour ambulatory $\mathrm{pH}$-impedance monitoring has the advantage of detecting all reflux (liquid, gas, or mixed) regardless of acidity. The Lyon consensus proposes that $>80$ reflux episodes per 24 hours are definitively abnormal, but an abnormal number of reflux episodes' clinical relevance remains incompletely defined. Therefore, its additional diagnostic benefit is still limited, although 24-hour ambulatory $\mathrm{pH}$-impedance monitoring is an adjunctive measure to be used when AET is inconclusive. ${ }^{34,108}$

Wireless $\mathrm{pH}$ monitoring increases the sensitivity of reflux detection by extending recording time to 48-96 hours, ${ }^{109-111}$ and is useful in patients who cannot tolerate trans-nasal catheter insertion. $^{112,113}$

Symptom index and symptom association probability are the parameters to evaluate symptom-reflux association, which have a predictive value for the effect of medical treatment of reflux disease. $^{114,115}$

\section{Esophageal Manometry}

Statement 14: Esophageal manometry is useful in
assessing the peristaltic function and exclusion of al-
ternative motility disorders. Therefore, esophageal
manometry should be performed before anti-reflux
surgery in patients with gastroesophageal reflux dis-
ease.
Level of evidence: low
Strength of recommendation, strong
Experts' opinions: agree strongly (57.8\%), agree with some
reservations ( $37.8 \%)$, undecided $(4.4 \%)$, disagree (0.0\%), and
disagree strongly $(0.0 \%)$

Esophageal manometry is often used to help accurate placement of pH-impedance catheters. Also, esophageal manometry helps assess patients who remain symptomatic despite the sufficient period of acid-suppressive therapy. It provides information regarding alternative diagnoses such as achalasia, distal esophageal spasm, 
or hypercontractile disorders. ${ }^{74}$ Manometric evaluation should be performed prior to considering surgery to rule out esophageal motility disorder and establish the adequacy of peristaltic reverse. ${ }^{116,117}$

High-resolution manometry (HRM) findings in GERD include hypotensive LES, hiatal hernia, and esophageal hypomotility. ${ }^{6,116,118}$ The most fundamental abnormality in GERD is the incompetence of the EGJ as an anti-reflux barrier, although a certain degree of EGJ incompetence is physiological. ${ }^{119}$ The recently proposed Lyon consensus suggested using 2 HRM metrics to assess EGJ competence; EGJ morphology (defined by the relationship between the intrinsic LES and the crural diaphragm) and EGJ contractile integral. ${ }^{6}$ In a previous study, defective EGJ contractile integral is associated with increased reflux episodes and esophageal acid exposure. ${ }^{120}$

Ineffective esophageal motility is the most common motor disorder in patients with proven GERD, which impairs esophageal clearance and prolongs the period during which refluxate may damage esophageal mucosa. ${ }^{116,121}$ Besides, peristalsis can be fragmented or absent, with or without a contractile reserve, in patients with GERD. Previous studies showed that the severity of peristaltic dysfunction is correlated with the burden of reflux symptoms, with the highest burden being in absent peristalsis. ${ }^{122,123}$ However, neither a decreased LES pressure nor the presence of esophageal hypomotility is specific enough to diagnose GERD ${ }^{30,122}$ Indeed, there are considerable overlaps between patients with GERD and healthy subjects, limiting the clinical relevance of HRM findings for GERD diagnosis.

\section{Novel Impedance Parameters}

Statement 15: Novel impedance parameters, includ-
ing baseline impedance and post-reflux swallow-
induced peristaltic wave, are promising in diagnosis of
gastroesophageal reflux disease and increase gastro-
esophageal reflux disease diagnostic yield.
$\quad$ Level of evidence: low
$\quad$ Strength of recommendation: weak
Experts' opinions: agree strongly (11.1\%), agree with some
reservations $(68.9 \%)$, undecided $(20.0 \%)$, disagree $(0.0 \%)$, and
disagree strongly $(0.0 \%)$

Two novel impedance parameters, including baseline impedance and post-reflux swallow-induced peristaltic wave (PSPW), have been suggested as additional diagnostic tests in GERD diagnosis. ${ }^{6,84,124-126}$ Baseline impedance reflects the esophageal mucosa's permeability, even in the absence of macroscopic damage. ${ }^{127}$ The
PSPW index assesses the competence of esophageal refluxate clearance. Baseline mucosal impedance of the esophagus is correlated with the degree of disruption of intercellular spaces and their tight junction. It is normalized with effective treatment, suggesting baseline mucosal impedance as a predictor of treatment response. ${ }^{128,129}$ Moreover, lower values of mean nocturnal baseline impedance and PSPW accurately distinguished patients with EE or NERD from healthy controls or those with functional heartburn. ${ }^{128,130-132}$ While these parameters can be utilized as complementary tools in the diagnosis of GERD, the need for manual calculation and the presence of day-to-day variability limit its generalized use.

\section{Treatment}

\section{Weight Reduction}

Statement 16: Weight reduction is recommended to
improve gastroesophageal reflux disease symptoms in
overweight patients or those diagnosed with obesity.
Level of evidence: moderate
Strength of recommendation: strong
Experts' opinions: agree strongly $(80.0 \%)$, agree with some
reservations $(17.8 \%)$, undecided (2.2\%), disagree $(0.0 \%)$, and
disagree strongly $(0.0 \%)$

Obesity is considered a risk factor for GERD ${ }^{133,134}$ Overweight and obesity are associated with increased intra-abdominal pressure, predisposition to hiatal hernia development, and gastroesophageal reflux. ${ }^{135}$ Several population-based studies have shown a significant relationship between increasing body mass index (BMI) and GERD. ${ }^{136-138}$ The Nurses' Health Study, an observational cohort study of 10545 women, showed that an increase in BMI of more than $3.5 \mathrm{~kg} / \mathrm{m}^{2}$, compared with those with no BMI change, was associated with an increased risk of reflux symptoms even in women with a normal baseline BMI (OR, 2.80; 95\% CI, 1.63-4.82). ${ }^{139}$ These epidemiologic associations have been confirmed in a recent systematic review, showing that the prevalence of GERD was significantly higher in the obese compared with non-obese subjects (OR, 1.73; 95\% CI, 1.46-2.06). ${ }^{140}$

The effect of weight reduction as a treatment for GERD has been evaluated in several studies (Supplementary Table 4). ${ }^{134,141-145}$ Previous RCTs compared weight loss by an intra-gastric balloon with sham treatment combined with a weight reduction program, and showed that body weight and visceral fat loss were associated with decreased total reflux time. ${ }^{143}$ Multiple cohort studies have 
demonstrated a significant reduction in reflux symptoms with weight loss. ${ }^{134,141,144}$ The HUNT study, a large prospective population-based cohort study including 29610 participants, showed that weight loss was dose-dependently associated with decrease or resolution of reflux symptoms. ${ }^{142}$ Also, a reduction in BMI was associated with increased treatment success. A recent retrospective longitudinal study investigating 15295 Korean individuals also found that decreased BMI was associated with symptom improvement in patients with EE. ${ }^{146}$ In another study, there was a dose-dependent relationship between a decreased $\mathrm{BMI}$ and resolution of $\mathrm{EE}$ in patients with obesity. ${ }^{147}$ Contrary to the above results, other studies did not show any effect of weight loss on reflux symptoms. ${ }^{145,148}$

Lifestyle interventions leading to weight reduction may be recommended for symptom control in patients with GERD who are overweight or with obesity. Although RCT and data on the longterm effect are limited, observational studies showed symptom improvement after weight reduction. Further studies need to elucidate which GERD patients and weight reduction would have a beneficial impact.

\section{Proton Pump Inhibitors}

\section{Initial treatment of gastroesophageal reflux disease with proton pump inhibitors}

Statement 17: The administration of a standard dose of proton pump inhibitors once a day for 4 weeks to 8 weeks is recommended as the initial treatment of gastroesophageal reflux disease.

Level of evidence: high

Strength of recommendation: strong

Experts' opinions: agree strongly $(77.8 \%)$, agree with some reservations $(22.2 \%)$, undecided $(0.0 \%)$, disagree $(0.0 \%)$, and disagree strongly $(0.0 \%)$

In patients with reflux esophagitis, once-daily treatment with a standard dose of PPIs results in complete relief in about $70-80 \%$ of patients with ERD and $60 \%$ of patients with NERD. ${ }^{30}$ It has been estimated that $20-40 \%$ of GERD patients fail to respond symptomatically to a standard dose PPIs. ${ }^{149}$

Comparison between proton pump inhibitors and histamine $\mathrm{H} 2$ receptor antagonists in gastroesophageal reflux disease

PPIs have been shown to be superior to histamine $\mathrm{H} 2$ receptor antagonists (H2RAs) in the treatment of GERD. In EE, PPI therapy showed better symptomatic control and mucosal healing effects compared to H2RA. ${ }^{150}$ In the meta-analysis comparing PPIs and H2RAs, the RR of symptoms persistence by the PPIs was 0.67 (95\% CI, 0.57-0.80) compared to that of H2RAs. ${ }^{151}$ In patients with reflux esophagitis, once-daily treatment with a standard dose of PPIs for 8 weeks results in a healing rate of $85-96 \% .^{152}$

For patients with NERD, PPI is more effective at relieving reflux symptoms compared to H2RA. In the Cochrane systematic review, PPI is more effective in improving reflux symptoms than H2RA in NERD patients. (RR, 0.78; 95\% CI, 0.62-0.97). ${ }^{153}$

Treatment for gastroesophageal reflux disease refractory to standard-dose proton pump inhibitor therapy

Double dose proton pump inhibitor therapy.

Statement 18: Double-dose proton pump inhibitor
therapy may be effective in patients with gastroesoph-
ageal reflux disease who do not show an adequate
response to standard-dose proton pump inhibitor
therapy.
$\quad$ Level of evidence: moderate
$\quad$ Strength of recommendation: weak
Experts' opinions: agree strongly (42.2\%), agree with some
reservations $(53.3 \%)$, undecided $(2.2 \%)$, disagree (2.2\%), and
disagree strongly $(0.0 \%)$

In case of insufficient response to the standard-dose PPI, a double-dose PPI can be administered. A standard-dose of PPI is administered twice a day before breakfast and dinner to achieve response. We searched for RCTs comparing double-dose PPI and standard-dose PPI and found 3 RCTs that matched these conditions. One study enrolled patients who had reflux esophagitis (LA classification grade A-D) at screening examination despite receiving a standard-dose PPI regimen. ${ }^{154}$ Another study included the patients who had reported heartburn of at least moderate severity on $>2$ in the previous 7 days despite using medication. ${ }^{155} \mathrm{At}$ 4 weeks, symptom resolution was higher in the double-dose PPI group but not statistically significant (RR, 1.31; 95\% CI, 0.99-1.73) (Supplementary Fig. 10). At 8 weeks, the symptom resolution was significantly higher in the double-dose PPI group (RR, 1.29; $95 \%$ CI, 1.15-1.45) (Supplementary Fig. 11) and the number neededto-treatment (NNT) was 5.3. Only one study evaluated endoscopic healing at 8 weeks. In the double-dose PPI group, healing was shown in $77.0 \%$ (77/100), and symptom resolution was significantly higher than in $58.8 \%(60 / 102)$ of the standard-dose PPI group $(P=0.003) .{ }^{154}$ Therefore, in patients who do not respond 
sufficiently to the standard-dose of PPI, double-dose PPI may be helpful.

Switching to other proton pump inhibitors. If the response to the standard-dose PPI therapy is not sufficient, switching to other PPIs is common in clinical practice, but the evidence for this is limited. In the initial treatment, there was little difference in the effect between different types of PPIs. One RCT study showed that in patients with persistent heartburn despite once-daily lansoprazole $30 \mathrm{mg}$, switching to esomeprazole $40 \mathrm{mg}$ once daily was as effective as increasing to twice-daily lansoprazole. ${ }^{137}$ Therefore, if the response to one type of PPI is not sufficient, switching to another type of standard-dose PPIs may be considered. However, more research is needed on its effectiveness.

The standard treatment in this clinical guideline refers to omeprazole $20 \mathrm{mg}$, lansoprazole $30 \mathrm{mg}$, pantoprazole $40 \mathrm{mg}$, rabeprazole $20 \mathrm{mg}$, and esomeprazole $40 \mathrm{mg}$. The treatment efficacy of these PPIs in standard treatment seems to be similar. However, RCTs comparing esomeprazole with other types of PPIs showed conflicting results. In the meta-analysis of these RCTs comparing esomeprazole versus other PPIs in the treatment of EE, there was a modest benefit of esomeprazole in mucosal healing and symptom relief. ${ }^{157}$ Specifically, at 8 weeks of healing, authors found an absolute risk reduction of $4 \%$, yielding an NNT of 25. Esomeprazole also showed significant symptomatic relief at 4 weeks than other PPIs (RR, 1.08; 95\% CI, 1.05-1.11). Recent network metaanalysis comparing different doses of PPIs and H2RAs in GERD showed that esomeprazole $40 \mathrm{mg}$ per day was the most efficient in esophagitis healing and symptom relief among 9 different dosages of PPIs and H2RAs. ${ }^{158}$ We conducted a meta-analysis, including 15 RCTs comparing esomeprazole $40 \mathrm{mg}$ with other PPIs' standard treatment. Esomeprazole $40 \mathrm{mg}$ per day increased the probability of symptomatic relief at 4 weeks (RR, 1.06; 95\% CI, 1.011.12) (Supplementary Fig. 12) and healing at 8 weeks (RR, 1.04; 95\% CI, 1.02-1.07) compared to other PPIs (Supplementary Fig. 13). NNT for symptom relief at 4 weeks was 13.8. However, since the difference in absolute effects is very small, as mentioned above, the effect of symptomatic improvement according to the type of PPIs currently available is not expected to be significant.

\section{On-demand proton pump inhibitor versus continuous daily proton pump inhibitor for long-term management}

Statement 19: The effectiveness of on-demand proton pump inhibitor therapy is comparable with that of continuous daily proton pump inhibitor therapy for the long-term management of patients with nonerosive reflux disease or mild erosive reflux disease.

Level of evidence: moderate

Strength of recommendation: weak

Experts' opinions: agree strongly (31.1\%), agree with some reservations $(57.8 \%)$, undecided (11.1\%), disagree $(0.0 \%)$, and disagree strongly $(0.0 \%)$

GERD is a chronic condition with relapse in about $50-80 \%$ of patients despite sufficient symptom control and mucosal healing by PPIs. ${ }^{159-161}$ In general, long term management of GERD is needed both for control of sustained reflux symptoms despite 4 weeks or 8 weeks of PPI therapy and for prevention of complications, such as esophageal adenocarcinoma resulting from chronic acid reflux in Barrett's esophagitis. ${ }^{162-164}$

Several forms of maintenance therapy, such as on-demand therapy, intermittent therapy, and threshold therapy, have been attempted for long-term management of GERD. Continuous therapy is defined as taking PPIs daily. On-demand PPI therapy means taking PPIs only when symptoms occur. Intermittent therapy is taking PPIs for a certain period after a relapse of symptoms. Threshold therapy means to gradually increase the interval between PPIs as long as symptoms do not recur.

We searched and identified 7 RCTs $(\mathrm{n}=5174)$ directly comparing the efficacy of continuous daily PPIs and on-demand PPIs in the long-term management of GERD patients (Supplementary Table 5). ${ }^{165-171}$ Outcomes of interest were the failure of PPI treatment in the long-term management of GERD, which was defined as either premature discontinuation due to unsatisfactory symptom control or need for a change of regimen. The proportions of PPI treatment failure in long-term management were $9.4 \%$ with ondemand PPI and $6.6 \%$ with continuous daily PPI. However, the risk of failure of on-demand PPI therapy was comparable with that of continuous therapy in the long-term management of GERD (RR, 1.46; 95\% CI, 0.90-2.38) (Supplementary Fig. 14). There was no significant difference in the treatment failure between ondemand and continuous daily PPI therapy in NERD and mild EE in the subgroup analysis. However, continuous daily PPI therapy was superior to on-demand PPI therapy in the EE group (RR, 
4.24; 95\% CI, 2.32-7.77), except for only 1 study (Supplementary Fig. 15). Also, patients' satisfaction for long-term management of GERD did not differ between both groups (RR, 0.96; 95\% CI, 0.92-1.00) (Supplementary Fig. 16). However, continuous daily PPI therapy was associated with a higher pill burden (RR, -0.46 ; 95\% CI, -0.54--0.38) (Supplementary Fig. 17). Although we did not perform cost analysis, continuous daily PPI therapy might be higher in cost expenses than on-demand PPI therapy.

Therefore, on-demand PPI therapy has comparable efficacy to continuous daily PPI therapy for GERD's long-term management concerning PPI. Considering patients' preferences and costeffectiveness, on-demand PPI therapy may replace continuous PPI therapy in patients with NERD or mild EE.

\section{Proton pump inhibitors for non-cardiac chest pain}

\section{Statement 20: Proton pump inhibitor therapy is rec- ommended to treat non-cardiac chest pain in patients with concomitant typical gastroesophageal reflux dis- ease symptoms.}

Level of evidence: moderate

Strength of recommendation: strong

Experts' opinions: agree strongly (46.7\%), agree with some reservations $(51.1 \%)$, undecided $(2.2 \%)$, disagree $(0.0 \%)$, and disagree strongly $(0.0 \%)$

Because GERD is one of the most common causes of NCCP, the diagnosis and therapeutic interventions of NCCP should focus first on GERD. In the Asia-Pacific consensus on the management of GERD, a therapeutic PPI test is the most pragmatic approach for suspected GERD-related NCCP due to the low sensitivity or limited accessibility of other tests. ${ }^{17}$

Until now, 7 RCTs ( $\mathrm{n}=965$ ) evaluated the treatment efficacy of a PPI in patients with NCCP (Fig. 1). ${ }^{172-178}$ In 6 RCTs (except 1 study), PPIs' effect was evaluated according to GERD's presence or absence (GERD positive: 1 or more typical symptoms per week or confirmed by upper endoscopy and/or 24-hour ambulatory pHimpedance monitoring). The pooled OR to produce a reduction of chest pain or the resolution of symptoms in GERD positive patients was 3.61 (95\% CI, 2.46-5.29) using the definition of individual studies (Supplementary Fig. 18). However, our meta-analysis found no significant benefits from PPI treatment in GERD negative patients with NCCP (OR, 1.0; 95\% CI, 0.70-1.42) (Supplementary Fig. 19). This finding suggests that PPI treatment was effective in GERD positive patients or typical GERD symptoms.

Previous studies have shown PPI efficacy in treating patients with NCCP, but optimal dose and duration of PPI treatment were inconsistent. Besides, the definition of a positive test has not been established yet. However, most studies used double-dose PPIs and recommended $\geq 8$ weeks of PPI treatment in other extra-esophageal symptoms, double-dose PPI treatment of 8 weeks or more in patients with NCCP who have the concomitant typical GERD symptoms was an effective treatment strategy. However, evidence of PPI therapy in NCCP patients who do not have typical symptoms of GERD is lacking.

\section{Proton pump inhibitors in Barrett's esophagus}

Barrett's esophagus is defined as the presence of at least $1 \mathrm{~cm}$ of metaplastic columnar epithelium that replaces the stratified squamous epithelium normally lining the distal esophagus. ${ }^{179}$ Barrett's esophagus is a well-known risk factor for esophageal adenocarcinoma. ${ }^{180,181}$ To prevent the progression of Barrett's esophagus to adenocarcinoma, routine endoscopic surveillance and endoscopic eradication therapy may be recommended for a subset of patients with high-grade dysplasia. ${ }^{180,182}$ However, not all patients with Barrett's esophagus can be treated with endoscopic eradication therapy due to the cost and its potential adverse events. PPIs have been suggested as a chemopreventive agent that prevents or delays the progression of Barrett's esophagus to high-grade dysplasia or adenocarcinoma.

Until now, several case-control and cohort studies have evaluated this issue. ${ }^{183-190}$ In the 3 case-control studies, the OR of PPI medication in terms of the risk of progression into high-grade dysplasia or adenocarcinoma was 0.36 (95\% CI, 0.09-1.44). ${ }^{183-185}$ Additionally, the pooled $\mathrm{HR}$ was 0.33 (95\% CI, 0.20-0.54) in the 5 cohort studies (Supplementary Fig. 20). ${ }^{186-190}$ The pooled effect size was similar between the case-control and cohort studies, although heterogeneity was identified in the case-control studies. In other words, PPI medication may reduce the risk of progression to highgrade dysplasia or adenocarcinoma by approximately $65.0 \%$ in patients with Barrett's esophagus.

However, the statement for the current key question-PPIs are recommended for patients with Barrett's esophagus to reduce the risk of progression to high-grade dysplasia or adenocarcinomawas rejected through experts' consensus voting. Despite the chemopreventive effect of PPIs proven in previous studies, we should be careful to generalize the results, especially in Asian populations, because all previous studies were performed in Western countriesthe United States of America (USA), Europe, and Australia. Besides, the prevalence of Barrett's esophagus is relatively low in Asia, and the short-segment type is common in Asian patients with 
Barrett's esophagus. ${ }^{17}$ Impact of PPI therapy in Asian patients with Barrett's esophagus should be further evaluated.

\section{Proton pump inhibitor use and potential risks}

Because of the effect of PPIs on the inhibition of gastric acid secretion, the use of PPIs can induce abnormal intestinal bacterial growth and increase the infection of bacteria such as Salmonella, Campylobacter, Escherichia coli, and Clostridium difficile. ${ }^{191,192}$ An RCT evaluating this issue reported that patients taking $40 \mathrm{mg}$ of pantoprazole daily over 3 years demonstrated a significant increase of enteric infection than that in a control group (OR, $1.33 ; 95 \% \mathrm{CI}$, 1.01-1.75). ${ }^{193}$ The NNT harm in this analysis was $>300$ with 3 years of PPI use. Therefore, in most situations, the PPI use indication is that benefit should likely outweigh the risk of enteric infection. Notably, the incidence of other adverse events such as myocardial infarction, stroke, cancers, hospitalization, pneumonia, fracture, chronic kidney disease, and dementia did not differ significantly between groups.

Many observational studies of the association between the use of PPI and the incidence of $C$. difficile infection (CDI) have been published. A meta-analysis of these studies showed that the use of PPI was associated with an increased incidence of overall CDI, hospital-acquired CDI, community-acquired CDI, and recurrent CDI ${ }^{194-199}$

We also conducted a meta-analysis of cohort studies studying the association between PPI and CDI. A meta-analysis of 16 cohort studies in adults showed that the use of PPI was significantly associated with an increase in CDI (OR, 2.03; 95\% CI, 1.52-2.72) (Supplementary Fig. 21). Based on the evidence suggesting that PPI increases enteric infection and from many meta-analyses of observational studies, we conclude that PPI's use may increase CDI incidence. However, because CDI incidence is lower than the incidence of enteric infection, the NNT harm is also considered much greater, so the absolute risk is very low.

Taken together, the use of PPI may increase the risk of enteric infection and $C$. difficile infection. However, the increase in risk is thought to be very small, as described above. So, the benefit is likely to be greater than the risk in the cases where PPIs are indicated. Even if the risk increase of enteric infection and CDI is small, it is recommended to use PPIs in the lowest effective dose for the shortest duration possible. However, in the first voting, only $62.2 \%$ of experts agreed, and in the second voting, only $65.1 \%$ of experts agreed. Thus, the statement regarding the risk of PPI was dismissed.

\section{Potassium-competitive Acid Blockers}

Statement 21: The efficacy of potassium-competitive
acid blockers is comparable to proton pump inhibi-
tors; hence they are recommended as an initial treat-
ment of gastroesophageal reflux disease.
Level of evidence: moderate
Strength of recommendation: strong
Experts' opinions: agree strongly (66.7\%), agree with some
reservations ( $33.3 \%)$, undecided $(0.0 \%)$, disagree $(0.0 \%)$, and
disagree strongly $(0.0 \%)$

Potassium-competitive acid blockers (P-CABs) bind competitively and reversibly to the potassium-binding site of the $\mathrm{H}^{+} / \mathrm{K}^{+}$ ATPase. P-CABs were first developed in the $1980 \mathrm{~s}^{200}$ However, many P-CABs did not show superior effects to conventional PPIs, and their development discontinued due to hepatotoxicity. ${ }^{201}$ Two $\mathrm{P}-\mathrm{CABs}$ (vonoprazan and tegoprazan) are currently indicated in patients with EE.

Vonoprazan was launched in 2015 in Japan. It was approved for the treatment of EE in Japan. ${ }^{201}$ Until now, 3 RCTs, including an Asian multicenter study, have shown that the efficacy of vonoprazan is not inferior to that of lansoprazole in patients with $\mathrm{EE} .{ }^{202-204}$ Also, a recent network meta-analysis suggested that the healing effect of vonoprazan on GERD is higher than that of rabeprazole. ${ }^{205}$ Tegoprazan was developed in South Korea, and it was approved for the treatment of EE and NERD. ${ }^{206-209}$ A recent phase III study showed the non-inferiority of tegoprazan $50 \mathrm{mg}$ and $100 \mathrm{mg}$ 's safety and efficacy to those of esomeprazole $40 \mathrm{mg}$ in patients with $\mathrm{EE} .^{208}$ The EE healing rate of vonoprazan at 2 weeks and 4 weeks and tegoprazan at 4 weeks also showed non-inferiority compared with PPIs. ${ }^{202-204,206}$

In the $4 \mathrm{RCT}$ s of $\mathrm{P}-\mathrm{CABs}$, including vonoprazan and tegoprazan, the EE healing rates of P-CABs at 8 weeks were not inferior to PPIs (pooled RR, 1.02; 95\% CI, 0.99-1.04) (Supplementary Fig. 22) ${ }^{202-204,206}$ The incidence of short-term adverse events was comparable between P-CABs and PPIs. ${ }^{202-204,206}$ From this result, the efficacy of P-CABs for 4 weeks and 8 weeks is comparable to PPIs. Therefore, $\mathrm{P}-\mathrm{CABs}$ are recommended as the initial treatment of GERD.

Three RCTs of vonoprazan conducted the subgroup analysis regarding severe EE drug efficacy (LA classification grade $\mathrm{C}$ and D) ${ }^{202-204}$ In patients with severe $\mathrm{EE}$, the healing rates were higher in vonoprazan than PPIs. ${ }^{202-204}$ There was no subgroup analysis of severe EE in a study with tegoprazan. ${ }^{206}$ Although the number of 
patients with severe EE was small, the treatment with tegoprazan also showed high healing rates $(100.0 \%)$ in severe EE (LA classification grade $\mathrm{C}$ and $\mathrm{D}){ }^{206}$ The results suggest that $\mathrm{P}-\mathrm{CAB}$ may be superior to PPIs in treating severe EE, although the accumulated evidence is insufficient. Further studies are needed to identify longterm maintenance therapy's efficacy and long-term safety outcomes of P-CABs in GERD.

\section{Histamine H2 Receptor Antagonists as Adjunctive Therapy in Nocturnal Acid Breakthrough}

Nocturnal intragastric $\mathrm{pH}<4.0$ lasting over 1 hour during PPI administration has been defined as nocturnal acid breakthrough (NAB). ${ }^{210}$ Because most PPIs have a short half-life and the efficacy is affected by meal-induced activation of proton pumps, even if the second dose of PPIs at night is administered, the new synthesis of gastric acid pumps at night cannot be suppressed entirely. $^{211}$ This provoked the potential preventive role of H2RAs on nocturnal histamine-driven gastric acid secretion, supporting H2RAs as an option for patients with incomplete control of nighttime symptoms despite optimal PPI use. ${ }^{212,213}$ Although the additional H2RAs treatment on PPI has been previously introduced in clinical practice; there is limited data to support this practice. Of the 3 double-blinded RCTs, 1 demonstrated that an additional administration of $\mathrm{H} 2 \mathrm{RAs}$ at bedtime is effective for preventing $\mathrm{NAB},{ }^{214}$ In comparison, the other $2 \mathrm{RCT}$ s failed to show the effectiveness of adding H2RAs on improving NAB or GERD. ${ }^{215,216}$ A metaanalysis with $8 \mathrm{RCT}$ has reported that additional bedtime H2RA decreases the percentage of time in which intragastric $\mathrm{pH}$ is $<4.0,{ }^{217}$ but the number of participants was only ${ }^{136}$ in each intervention and control group. Besides, more than half of the studies have been conducted in one country, possessing the possibility of bias. The subjects of some studies had different characteristics from GERD patients, such as systemic sclerosis or duodenal ulcer. The efficacy of adding H2RA may disappear after a month due to the tachyphylaxis of acid suppression. ${ }^{218}$

When considering the lack of sufficient prospective clinical trials for bedtime H2RA, adding H2RA before bedtime may be recommended in selected patients who have night-time reflux symptoms or objective evidence of overnight esophageal acid reflux despite the optimal use of PPIs.

\section{Prokinetics}

Since the introduction of PPIs in the drug market, PPIs were used as the treatment of choice of GERD. However, $30.0 \%$ of patients with GERD complain of symptoms despite administer- ing a standard dose of PPIs. ${ }^{219}$ Therefore, other adjunctive treatments were recommended in several guidelines. ${ }^{18,153}$ However, the evidence level of such treatments is weak. In patients with GERD, several studies reported that prokinetics showed additional benefits in improving GERD symptoms. ${ }^{220-222}$

According to our meta-analysis from 9 studies, the symptom improvement was $63.8 \%$ upon the addition of prokinetics over PPIs, compared to $50.6 \%$ in the PPI monotherapy. There was a statistically significant effect of PPIs plus prokinetics in reducing the global symptoms of GERD (RR, 1.22; 95\% CI, 1.11-1.35) with low heterogeneity $\left(\mathrm{I}^{2}=15 \% ; P=0.310\right)$ (Supplementary Fig. 23). In patients with refractory GERD, administration of PPIs plus prokinetics showed a significantly better improvement than with PPI monotherapy (RR, 1.47; 95\% CI, 1.15-1.88) with low heterogeneity $\left(\mathrm{I}^{2}=0 \% ; P=0.510\right)$ (Supplementary Fig. 24). Therefore, prokinetics may be administrated with PPIs to improve symptoms in patients with GERD. Despite a significant difference, there were some limitations, including small sample sizes and different outcome measurements in each meta-analysis study. Therefore, the expert consensus did not reach an agreement regarding the benefit of adding prokinetics to PPIs for improving symptoms in patients with GERD.

\section{Baclofen}

Baclofen, a $\gamma$-aminobutyric acid class $\mathrm{B}\left(\mathrm{GABA}_{\mathrm{B}}\right)$ agonist, has been demonstrated to be effective in GERD through its ability to reduce transient LES relaxations and reflux episodes. ${ }^{223-226}$ Baclofen has also been shown to decrease the number of postprandial acid and non-acid reflux events, nocturnal reflux activity, and belching episodes. ${ }^{227,228} \mathrm{~A}$ trial of baclofen at a dosage of 5-20 mg 3 times a day can be considered in patients with symptomatic reflux despite twice-daily PPI therapy. ${ }^{229}$

Neurological side effects such as dizziness, tiredness, sleepiness are commonly reported with the use of baclofen. A meta-analysis reported no serious adverse events or deaths related to the use of baclofen in GERD patients. Also, there were no significant differences in the overall adverse events between baclofen and placebo. All reported side effects of baclofen were of mild-to-moderate intensity, and the drug was well tolerated. ${ }^{230}$

\section{Alginate-based Therapy}

Alginate is a naturally occurring anionic polymer typically obtained from brown seaweed. Alginate reacts with gastric acid and makes raft-formation which prevents gastric acid regurgitation as a physical barrier. ${ }^{231}$ The 'acid pocket' is an unbuffered, highly 
acidic area of gastric secretion that accumulates in the proximal stomach postprandially. ${ }^{232}$ The acid pocket may cause postprandial acid reflux in patients with GERD. One Japanese study revealed that sodium alginate could eliminate or displace the post-prandial acid pocket in patients with GERD. ${ }^{233}$ Another study evaluated the efficacy of the alginate-antacid complex. ${ }^{234}$ In this RCT, alginate showed a more favorable symptomatic relief than placebo. Several studies also proved that alginate could decrease acid exposure in the postprandial period. ${ }^{235-237}$ Alginate showed a better clinical effect in reducing reflux-related symptoms than placebo or non-alginate antiacid. $^{238,239}$ In a meta-analysis, alginate-antacid also showed $60.0 \%$ relative benefit compared to placebo. ${ }^{240} \mathrm{~A}$ RCT in patients with NERD showed that alginate had similar clinical efficacy compared with PPI. $^{241}$

As an adjunctive therapy of PPIs, alginate failed to show better clinical efficacy in the symptomatic breakthrough in PPI-treated patients with GERD than placebo. ${ }^{242}$ A recent Korean RCT also did not demonstrate clinical benefits of adding alginate to PPI versus PPI alone. ${ }^{243}$ However, in a previous study from the United Kingdom, adding alginate could decrease the burden of symptoms in patients with residual reflux symptom despite PPI treatment. ${ }^{244}$ Asia-Pacific guideline-recommended alginate as a rescue medicine in patients with refractory GERD. ${ }^{17}$ Recent meta-analysis showed that alginate therapy is more effective than placebo or antacids for symptomatic improvement of patients with GERD. ${ }^{245}$ Alginate may be an effective and valuable agent in the treatment of patients with GERD.

\section{Endoscopic Therapy}

GERD's endoscopic therapies are minimally invasive treatments that fill the gap between pharmacological treatment and surgical fundoplication. Various novel methods of endoscopic therapy have been actively proposed over the last 2 decades in Western countries. They are classified into 3 categories. (1) endoscopic fundoplication: transoral incisionless fundoplication using endoscopic plication devices (EsophyX, EndoGastric Solutions, Inc, Redmond, WA, USA; Plicator, NDO Surgical, Mansfield, MA, USA; GERD-X; G-SURG, Germany; Endocinch; C.R. Bard Inc., Murray Hill, NJ, USA), (2) radiofrequency energy delivery (Stretta system; Curon Medical, Synnyvale, CA, USA), (3) reinforcement of the LES (LINX Reflux Management System, Torax Medical, Inc., Shoreview, Minn, USA; Enteryx; Boston Scientific Corp, Natick, MA, USA; Gatekeeper Reflux Repair System; Medtronic, Inc., Shoreview, MN, USA). Because of the lack of efficacy or the presence of complications, many of these techniques have been discontinued. Currently, trans-oral incisionless fundoplication using EsophyX, Medigus Ultrasonic Surgical Endostapler and Stretta device are available in USA.

Several meta-analyses have evaluated the clinical outcomes of the Stretta system. ${ }^{246-248}$ The most recent meta-analysis evaluated outcomes of 2468 patients from 4 RCTs, 23 cohort studies, and 1 registry with mean follow-up periods of 25.4 months. ${ }^{246}$ The pooled results showed that the Stretta improved the HRQOL score and reduced the pooled heartburn score, EE incidence, esophageal acid exposure, and the use of PPIs. However, out of the 28 studies, there were 4 RCTs with the limitation that there is no comparison with other procedures such as laparoscopic Nissen fundoplication. In a long-term observational study of 217 patients before and after Stretta, GERD-HRQOL scores, satisfaction, and PPI use significantly improved, which were immediate and durable at 10 years. ${ }^{249}$ In another meta-analysis of 4 trials with 153 patients with GERD, Stretta did not produce significant changes in physiologic parameters, including time spent at a $\mathrm{pH}<4$, LES pressure, ability to stop PPIs, or HRQOL compared with sham therapy. ${ }^{247}$

Most of endoscopic therapies for GERD have made great strides with short-term effectiveness, but a long-term outcome is still unclear. Moreover, treatment devices are not readily available. Endoscopic therapies can be considered in carefully selected patients.

\section{Anti-reflux Surgery}

Statement 22: Anti-reflux surgery can be recom-
mended as an alternative to proton pump inhibitor
maintenance therapy to improve symptoms and qual-
ity of life in patients with proven gastroesophageal
reflux disease.
reflux disease.

Level of evidence: moderate

Strength of recommendation: weak

Experts' opinions: agree strongly (22.2\%), agree with some reservations $(60.0 \%)$, undecided $(15.6 \%)$, disagree $(2.2 \%)$, and disagree strongly $(0.0 \%)$

Anti-reflux surgery is considered an effective treatment option for GERD and is widely performed in Western countries. Many clinical trials comparing anti-reflux surgery and PPIs for GERD have been conducted. These trials established that anti-reflux surgery is as effective as or more effective than PPI in controlling GERD symptoms over a follow-up period of 5 years. ${ }^{250-259}$ Also, several studies demonstrated that anti-reflux surgery was likely to be cost-effective compared to medical treatment. ${ }^{255,257,260}$ From the 


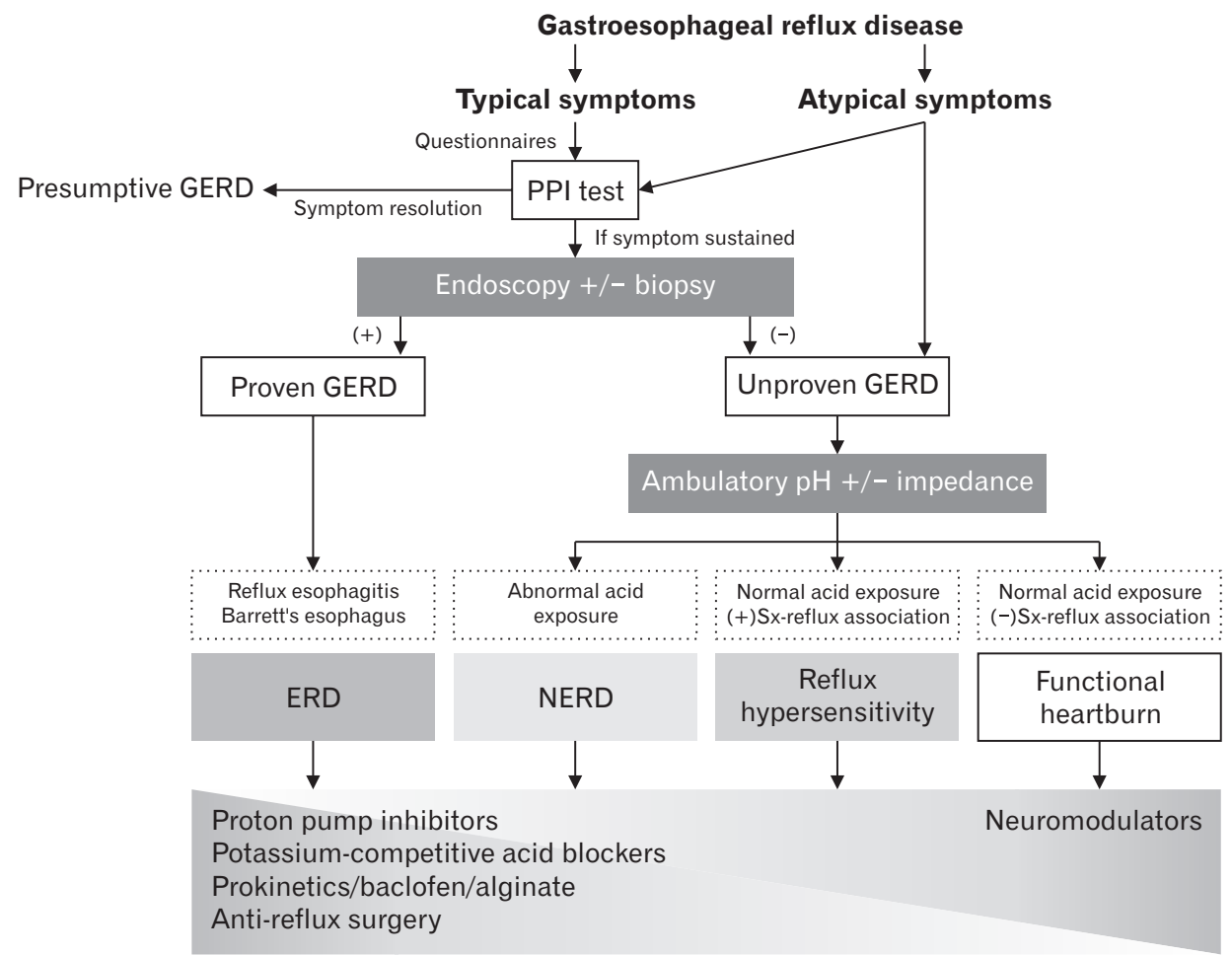

Figure 2. Algorithm for the diagnosis and treatment of gastroesophageal reflux disease. mid-2000s, clinical trials of laparoscopic anti-reflux surgery versus PPIs treatment have reported similar outcomes. $253-255,257,258,261,262$

A prospective randomized, open parallel-group multicenter trial comparing the efficacy and safety of laparoscopic anti-reflux surgery with that of esomeprazole $20 \mathrm{mg}$ or $40 \mathrm{mg}$ per day over 5 years in patients with chronic GERD demonstrated that esophageal acid exposure was significantly reduced in the laparoscopic antireflux surgery group $(n=116)$ compared with the PPI group $(\mathrm{n}=151) .{ }^{258}$ Moreover, several studies reported that anti-reflux surgery had a lower acid exposure of esophagus and higher pressure of LES than PPI treatment in short-term and long-term followup. $254,259,261$

In terms of cost-effectiveness of the anti-reflux surgery, one study compared the cost-effectiveness of laparoscopic surgery $(\mathrm{n}=$ $155)$ and medical management $(\mathrm{n}=104)$ using the data of a randomized multicenter trial. The results indicated that laparoscopic anti-reflux surgery is cost-effective, provided that its clinical benefits are sustained in the medium-to-long term. ${ }^{256}$ Recently, a Korean cost-effectiveness study reported that the anti-reflux surgery was less expensive and more effective therapy over the PPI pharmacotherapy after 9 years of follow-up. ${ }^{260}$ Physiological tests, such as a $24-$ hour esophageal $\mathrm{pH}$ study, should be performed to prove GERD before surgery, and other esophageal motility disorders should be excluded by conducting esophageal manometry. Anti-reflux surgery is an excellent treatment option with a better long-term effect and cost-effectiveness compared to the PPI therapy. In proven patients with proven GERD, laparoscopic anti-reflux surgery can be recommended as an alternative to PPI maintenance therapy.

\section{Conclusions and Perspectives}

The 2020 Seoul Consensus on evidence-based GERD Clinical Practice Guidelines has been developed via collaboration with experts from Asia using the systematic review and meta-analysis methods. The prevalence of GERD is rapidly increasing in Asia. These guidelines present standards for new diagnosis and treatment of GERD, ranging from primary care to gastroenterologists in Asia (Fig. 2). The extensive dissemination and applications of these guidelines across Asia will provide the best clinical outcomes for GERD. The present guidelines will be updated periodically in response to new evidence accumulation. Prospective studies on the diagnostic efficacy of novel impedance parameters, including baseline impedance, post-reflux swallow-induced peristaltic wave, and longterm therapeutic outcomes of P-CABs, including their benefits and harms, are still needed. 


\section{Supplementary Materials}

Note: To access the supplementary tables and figures mentioned in this article, visit the online version of Journal of Neurogastroenterology and Motility at http://www.jnmjournal.org/, and at https://doi.org/10.5056/jnm21077.

Acknowledgements: We are grateful to all who participated in this study. We thank Sanjiv Mahadeva (Malaysia), Myung-Gyu Choi (South Korea), and Shobna Bhatia (India) for the external review.

Financial support: This project was supported by the KSNM and a grant of Patient-Centered Clinical Research Coordinating Center funded by the Ministry of Health and Welfare, Republic of Korea (Grant No. HI19C0481 and HC19C0060).

\section{Conflicts of interest: None.}

Author contributions: Hye-Kyung Jung and Chung Hyun Tae have contributed in writing and editing the paper as the first authors; Mi-Young Choi helped in formulating clinical key questions, conducting relevant literatures search, and mentoring for extensive meta-analyses. Jong Kyu Park, Seung Joo Kang, Jung Min Lee, Seung Young Kim, Chan Hyuk Park, Da Hyun Jung, Joon Sung Kim, and Seung In Seo performed the meta-analysis, the extraction of recommendations, and writing the paper; Kyung Ho Song, Jeong Eun Shin, Hyun Chul Lim, Yoon Jin Choi, Beon Jin Kim, Sun Hyung Kang, Tae Hee Lee, Young Sin Cho, Eun Jeong Gong, Han Hong Lee, Kee Wook Jung, Do Hoon Kim, and Hee Seok Moon have contributed in the systematic review, the extraction of recommendations, and writing the paper; Sang Kil Lee, Suck Chei Choi, Joong Goo Kwon, Kyung Sik Park, Moo In Park participated in interpretation of data; Hirota Miwa, ChienLin Chen, Sutep Gonlachanvit, Uday C Ghoshal, Justin C Y Wu, Kewin T H Siah, Xiaohua Hou, and Tadayuki Oshima participated in Delphi survey for important intellectual content as expert panel; and Hye-Kyung Jung and Kwang Jae Lee have designed the guideline development as chairman of the guideline committee and KSNM, respectively, and have revised the manuscript critically.

\section{References}

1. Vakil N, van Zanten SV, Kahrilas P, Dent J, Jones R. The Montreal definition and classification of gastroesophageal reflux disease: a global evidence-based consensus. Am J Gastroenterol 2006;101:1900-1920.

2. Richter JE, Rubenstein JH. Presentation and epidemiology of gastroesophageal reflux disease. Gastroenterology 2018;154:267-276.

3. Pace F, Bianchi Porro G. Gastroesophageal reflux disease: a typical spectrum disease (a new conceptual framework is not needed). Am J Gastroenterol 2004;99:946-949.

4. Katzka DA, Pandolfino JE, Kahrilas PJ. Phenotypes of gastroesophageal reflux disease: where rome, Lyon, and Montreal meet. Clin Gastroenterol Hepatol 2020;18:767-776.

5. Aziz Q, Fass R, Gyawali CP, Miwa H, Pandolfino JE, Zerbib F. Functional esophageal disorders. Gastroenterology 2016;150:1368-1379.

6. Gyawali CP, Kahrilas PJ, Savarino E, et al. Modern diagnosis of GERD: the Lyon consensus. Gut 2018;67:1351-1362.

7. Jung HK, Hong SJ, Lee OY, et al. 2019 Seoul consensus on esophageal achalasia guidelines. J Neurogastroenterol Motil 2020;26:180-203.

8. Schünemann H, Brożek J, Guyatt G, Oxman A. Handbook for grading the quality of evidence and the strength of recommendations using the GRADE approach. 2013. https://med.mahidol.ac.th/ceb/sites/ default/files/public/pdf/journal club/2017/GRADE\%20handbook.pdf (accessed 5 Oct 2021).

9. Andrews J, Guyatt G, Oxman AD, et al. GRADE guidelines: 14. Going from evidence to recommendations: the significance and presentation of recommendations. J Clin Epidemiol 2013;66:719-725.

10. Ronkainen J, Aro P, Storskrubb T, et al. High prevalence of gastroesophageal reflux symptoms and esophagitis with or without symptoms in the general adult Swedish population: a Kalixanda study report. Scand J Gastroenterol 2005;40:275-285.

11. Savarino E, Tutuian R, Zentilin P, et al. Characteristics of reflux episodes and symptom association in patients with erosive esophagitis and nonerosive reflux disease: study using combined impedance- $\mathrm{pH}$ off therapy. Am J Gastroenterol 2010;105:1053-1061.

12. Savarino E, Zentilin P, Savarino V. NERD: an umbrella term including heterogeneous subpopulations. Nat Rev Gastroenterol Hepatol 2013;10:371-380.

13. Giacchino M, Savarino V, Savarino E. Distinction between patients with non-erosive reflux disease and functional heartburn. Ann Gastroenterol 2013;26:283-289.

14. Yamasaki T, Fass R. Reflux hypersensitivity: a new functional esophageal disorder. J Neurogastroenterol Motil 2017;23:495-503.

15. Savarino V, Marabotto E, Zentilin P, et al. Esophageal reflux hypersensitivity: non-GERD or still GERD? Dig Liver Dis 2020;52:1413-1420.

16. Sifrim D, Zerbib F. Diagnosis and management of patients with reflux symptoms refractory to proton pump inhibitors. Gut 2012;61:13401354.

17. Fock KM, Talley N, Goh KL, et al. Asia-Pacific consensus on the management of gastro-oesophageal reflux disease: an update focusing on refractory reflux disease and Barrett's oesophagus. Gut 2016;65:14021415 .

18. Iwakiri K, Kinoshita Y, Habu Y, et al. Evidence-based clinical practice guidelines for gastroesophageal reflux disease 2015. J Gastroenterol 2016;51:751-767.

19. Hunt R, Armstrong D, Katelaris P, et al. World gastroenterology organ- 
isation global guidelines: GERD global perspective on gastroesophageal reflux disease. J Clin Gastroenterol 2017;51:467-478.

20. Niu XP, Yu BP, Wang YD, et al. Risk factors for proton pump inhibitor refractoriness in Chinese patients with non-erosive reflux disease. World J Gastroenterol 2013;19:3124-3129.

21. Bytzer P, van Zanten SV, Mattsson H, Wernersson B. Partial symptomresponse to proton pump inhibitors in patients with non-erosive reflux disease or reflux oesophagitis - a post hoc analysis of 5796 patients. Aliment Pharmacol Ther 2012;36:635-643.

22. Carlsson R, Dent J, Watts R, et al. Gastro-oesophageal reflux disease in primary care: an international study of different treatment strategies with omeprazole. International GORD study group. Eur J Gastroenterol Hepatol 1998;10:119-124.

23. Bardhan KD. The role of proton pump inhibitors in the treatment of gastro-oesophageal reflux disease. Aliment Pharmacol Ther 1995;9(suppl 1):15-25.

24. El-Serag H, Becher A, Jones R. Systematic review: persistent reflux symptoms on proton pump inhibitor therapy in primary care and community studies. Aliment Pharmacol Ther 2010;32:720-737.

25. Fass R. Symptom assessment tools for gastroesophageal reflux disease (GERD) treatment. J Clin Gastroenterol 2007;41:437-444.

26. Lee ES, Kim N, Lee SH, et al. Comparison of risk factors and clinical responses to proton pump inhibitors in patients with erosive oesophagitis and non-erosive reflux disease. Aliment Pharmacol Ther 2009;30:154164.

27. Miwa H, Sasaki M, Furuta T, et al. Efficacy of rabeprazole on heartburn symptom resolution in patients with non-erosive and erosive gastrooesophageal reflux disease: a multicenter study from Japan. Aliment Pharmacol Ther 2007;26:69-77.

28. Furuta T, Shimatani T, Sugimoto M, et al. Investigation of pretreatment prediction of proton pump inhibitor (PPI)-resistant patients with gastroesophageal reflux disease and the dose escalation challenge of PPIsTORNADO study: a multicenter prospective study by the acid-related symptom research group in Japan. J Gastroenterol 2011;46:1273-1283.

29. Jung HK, Hong SJ, Jo YJ, et al. [Updated guidelines 2012 for gastroesophageal reflux disease]. Korean J Gastroenterol 2012;60:195-218. [Korean]

30. Katz PO, Gerson LB, Vela MF. Guidelines for the diagnosis and management of gastroesophageal reflux disease. Am J Gastroenterol 2013;108:308-328.

31. Amarasiri LD, Pathmeswaran A, de Silva HJ, Ranasinha CD. Prevalence of gastro-oesophageal reflux disease symptoms and reflux-associated respiratory symptoms in asthma. BMC Pulm Med 2010;10:49.

32. Madanick RD. Management of GERD-related chronic cough. Gastroenterol Hepatol (NY) 2013;9:311-313.

33. el-Serag HB, Sonnenberg A. Comorbid occurrence of laryngeal or pulmonary disease with esophagitis in United States military veterans. Gastroenterology 1997;113:755-760.

34. Zerbib F, Roman S, Ropert A, et al. Esophageal pH-impedance monitoring and symptom analysis in GERD: a study in patients off and on therapy. Am J Gastroenterol 2006;101:1956-1963.

35. Sansone RA, Sansone LA. Hoarseness: a sign of self-induced vomiting?
Innov Clin Neurosci 2012;9:37-41.

36. Fass R, Achem SR. Noncardiac chest pain: epidemiology, natural course and pathogenesis. J Neurogastroenterol Motil 2011;17:110-123.

37. Richter JE. Chest pain and gastroesophageal reflux disease. J Clin Gastroenterol 2000;30(3 suppl):S39-S41.

38. Park SH, Choi JY, Park EJ, et al. Prevalence of gastrointestinal diseases and treatment status in noncardiac chest pain patients. Korean Circ J 2015;45:469-472.

39. Locke GR 3rd, Talley NJ, Fett SL, Zinsmeister AR, Melton LJ 3rd. Prevalence and clinical spectrum of gastroesophageal reflux: a population-based study in Olmsted County, Minnesota. Gastroenterology 1997;112:1448-1456.

40. Min YW, Lim SW, Lee JH, et al. Prevalence of extraesophageal symptoms in patients with gastroesophageal reflux disease: a multicenter questionnaire-based study in Korea. J Neurogastroenterol Motil 2014;20:8793.

41. Jung HK. Epidemiology of gastroesophageal reflux disease in Asia: a systematic review. J Neurogastroenterol Motil 2011;17:14-27.

42. Kim JI, Kim SG, Kim N, et al. Changing prevalence of upper gastrointestinal disease in 28893 Koreans from 1995 to 2005. Eur J Gastroenterol Hepatol 2009;21:787-793.

43. Chen MJ, Lee YC, Chiu HM, Wu MS, Wang HP, Lin JT. Time trends of endoscopic and pathological diagnoses related to gastroesophageal reflux disease in a Chinese population: eight years single institution experience. Dis Esophagus 2010;23:201-207.

44. Lim SL, Goh WT, Lee JM, Ng TP, Ho KY. Changing prevalence of gastroesophageal reflux with changing time: longitudinal study in an Asian population. J Gastroenterol Hepatol 2005;20:995-1001.

45. Lien HC, Chang CS, Yeh HZ, et al. Increasing prevalence of erosive esophagitis among Taiwanese aged 40 years and above: a comparison between two time periods. J Clin Gastroenterol 2009;43:926-932.

46. Bolier EA, Kessing BF, Smout AJ, Bredenoord AJ. Systematic review: questionnaires for assessment of gastroesophageal reflux disease. Dis Esophagus 2015;28:105-120.

47. Jones R, Junghard O, Dent J, et al. Development of the GerdQ, a tool for the diagnosis and management of gastro-oesophageal reflux disease in primary care. Aliment Pharmacol Ther 2009;30:1030-1038.

48. Shaw MJ, Talley NJ, Beebe TJ, et al. Initial validation of a diagnostic questionnaire for gastroesophageal reflux disease. Am J Gastroenterol 2001;96:52-57.

49. Savarino E, Bredenoord AJ, Fox M, Pandolfino JE, Roman S, Gyawali CP. Expert consensus document: advances in the physiological assessment and diagnosis of GERD. Nat Rev Gastroenterol Hepatol 2017;14:665-676.

50. Dent J, Vakil N, Jones R, et al. Accuracy of the diagnosis of GORD by questionnaire, physicians and a trial of proton pump inhibitor treatment: the Diamond study. Gut 2010;59:714-721.

51. Zhang M, Pandolfino JE, Zhou X, et al. Assessing different diagnostic tests for gastroesophageal reflux disease: a systematic review and network meta-analysis. Therap Adv Gastroenterol 2019;12:1756284819890537.

52. Gyawali CP, Fass R. Management of gastroesophageal reflux disease. Gastroenterology 2018;154:302-318. 
53. Weijenborg PW, Smout AJ, Verseijden C, et al. Hypersensitivity to acid is associated with impaired esophageal mucosal integrity in patients with gastroesophageal reflux disease with and without esophagitis. Am J Physiol Gastrointest Liver Physiol 2014;307:G323-G329.

54. Roman S, Keefer L, Imam H, et al. Majority of symptoms in esophageal reflux PPI non-responders are not related to reflux. Neurogastroenterol Motil 2015;27:1667-1674.

55. Lundell LR, Dent J, Bennett JR, et al. Endoscopic assessment of oesophagitis: clinical and functional correlates and further validation of the Los Angeles classification. Gut 1999;45:172-180.

56. Bredenoord AJ, Hemmink GJ, Smout AJ. Relationship between gastrooesophageal reflux pattern and severity of mucosal damage. Neurogastroenterol Motil 2009;21:807-812.

57. Wang FW, Tu MS, Chuang HY, Yu HC, Cheng LC, Hsu PI. Erosive esophagitis in asymptomatic subjects: risk factors. Dig Dis Sci 2010;55:1320-1324.

58. Kim BJ, Cheon WS, Oh HC, Kim JW, Park JD, Kim JG. Prevalence and risk factor of erosive esophagitis observed in Korean national cancer screening program. J Korean Med Sci 2011;26:642-646.

59. Muthusamy VR, Lightdale JR, Acosta RD, et al. The role of endoscopy in the management of GERD. Gastrointest Endosc 2015;81:13051310 .

60. Kapel RC, Miller JK, Torres C, Aksoy S, Lash R, Katzka DA. Eosinophilic esophagitis: a prevalent disease in the United States that affects all age groups. Gastroenterology 2008;134:1316-1321.

61. Kim GH, Park YS, Jung KW, et al. An increasing trend of eosinophilic esophagitis in Korea and the clinical implication of the biomarkers to determine disease activity and treatment response in eosinophilic esophagitis. J Neurogastroenterol Motil 2019;25:525-533.

62. Byrne KR, Panagiotakis PH, Hilden K, Thomas KL, Peterson KA, Fang JC. Retrospective analysis of esophageal food impaction: differences in etiology by age and gender. Dig Dis Sci 2007;52:717-721.

63. Veerappan GR, Perry JL, Duncan TJ, et al. Prevalence of eosinophilic esophagitis in an adult population undergoing upper endoscopy: a prospective study. Clin Gastroenterol Hepatol 2009;7:420-426, e1-e2.

64. Kandulski A, Jechorek D, Caro C, et al. Histomorphological differentiation of non-erosive reflux disease and functional heartburn in patients with PPI-refractory heartburn. Aliment Pharmacol Ther 2013;38:643651.

65. Wang KK, Sampliner RE. Updated guidelines 2008 for the diagnosis, surveillance and therapy of Barrett's esophagus. Am J Gastroenterol 2008;103:788-797.

66. Codipilly DC, Chandar AK, Singh S, et al. The effect of endoscopic surveillance in patients with Barrett's esophagus: a systematic review and meta-analysis. Gastroenterology 2018;154:2068-2086, e5.

67. Corley DA, Levin TR, Habel LA, Weiss NS, Buffler PA. Surveillance and survival in Barrett's adenocarcinomas: a population-based study. Gastroenterology 2002;122:633-640.

68. El-Serag HB, Naik AD, Duan Z, et al. Surveillance endoscopy is associated with improved outcomes of oesophageal adenocarcinoma detected in patients with Barrett's oesophagus. Gut 2016;65:1252-1260.

69. Royston C, Caygill C, Charlett A, Bardhan KD. The evolution and out- come of surveillance of Barrett's oesophagus over four decades in a UK district general hospital. Eur J Gastroenterol Hepatol 2016;28:13651373 .

70. Theron BT, Padmanabhan H, Aladin H, et al. The risk of oesophageal adenocarcinoma in a prospectively recruited Barrett's oesophagus cohort. United European Gastroenterol J 2016;4:754-761.

71. Verbeek RE, Leenders M, Ten Kate FJ, et al. Surveillance of Barrett's esophagus and mortality from esophageal adenocarcinoma: a populationbased cohort study. Am J Gastroenterol 2014;109:1215-1222.

72. Chandrasekar VT, Hamade N, Desai M, et al. Significantly lower annual rates of neoplastic progression in short- compared to long-segment non-dysplastic Barrett's esophagus: a systematic review and metaanalysis. Endoscopy 2019;51:665-672.

73. Herregods TV, Troelstra M, Weijenborg PW, Bredenoord AJ, Smout AJ. Patients with refractory reflux symptoms often do not have GERD. Neurogastroenterol Motil 2015;27:1267-1273.

74. Galindo G, Vassalle J, Marcus SN, Triadafilopoulos G. Multimodality evaluation of patients with gastroesophageal reflux disease symptoms who have failed empiric proton pump inhibitor therapy. Dis Esophagus 2013;26:443-450.

75. Dickman R, Boaz M, Aizic S, Beniashvili Z, Fass R, Niv Y. Comparison of clinical characteristics of patients with gastroesophageal reflux disease who failed proton pump inhibitor therapy versus those who fully responded. J Neurogastroenterol Motil 2011;17:387-394.

76. Gunaratnam NT, Jessup TP, Inadomi J, Lascewski DP. Sub-optimal proton pump inhibitor dosing is prevalent in patients with poorly controlled gastro-oesophageal reflux disease. Aliment Pharmacol Ther 2006;23:1473-1477.

77. Hemmink GJ, Bredenoord AJ, Weusten BL, Monkelbaan JF, Timmer $\mathrm{R}$, Smout AJ. Esophageal $\mathrm{pH}$-impedance monitoring in patients with therapy-resistant reflux symptoms: 'on' or 'off' proton pump inhibitor? Am J Gastroenterol 2008; 103:2446-2453.

78. Boeckxstaens GE, Smout A. Systematic review: role of acid, weakly acidic and weakly alkaline reflux in gastro-oesophageal reflux disease. Aliment Pharmacol Ther 2010;32:334-343.

79. Kohata Y, Fujiwara Y, Machida H, et al. Pathogenesis of proton-pump inhibitor-refractory non-erosive reflux disease according to multichannel intraluminal impedance-pH monitoring. J Gastroenterol Hepatol 2012;27(suppl 3):58-62.

80. Park EY, Choi MG, Baeg M, et al. The value of early wireless esophageal $\mathrm{pH}$ monitoring in diagnosing functional heartburn in refractory gastroesophageal reflux disease. Dig Dis Sci 2013;58:2933-2939.

81. Abdallah J, George N, Yamasaki T, Ganocy S, Fass R. Most patients with gastroesophageal reflux disease who failed proton pump inhibitor therapy also have functional esophageal disorders. Clin Gastroenterol Hepatol 2019;17:1073-1080, e1.

82. Iwakiri K, Kawami N, Sano H, et al. Acid and non-acid reflux in Japanese patients with non-erosive reflux disease with persistent reflux symptoms, despite taking a double-dose of proton pump inhibitor: a study using combined pH-impedance monitoring. J Gastroenterol 2009;44:708712.

83. Mainie I, Tutuian R, Shay S, et al. Acid and non-acid reflux in patients 
with persistent symptoms despite acid suppressive therapy: a multicentre study using combined ambulatory impedance-pH monitoring. Gut 2006;55:1398-1402.

84. Roman S, Gyawali CP, Savarino E, et al. Ambulatory reflux monitoring for diagnosis of gastro-esophageal reflux disease: update of the porto consensus and recommendations from an international consensus group. Neurogastroenterol Motil 2017;29:1-15.

85. Wiener GJ, Morgan TM, Copper JB, et al. Ambulatory 24-hour esophageal $\mathrm{pH}$ monitoring. Reproducibility and variability of $\mathrm{pH}$ parameters. Dig Dis Sci 1988;33:1127-1133.

86. Patel A, Sayuk GS, Gyawali CP. Prevalence, characteristics, and treatment outcomes of reflux hypersensitivity detected on $\mathrm{pH}$-impedance monitoring. Neurogastroenterol Motil 2016;28:1382-1390.

87. Patel A, Sayuk GS, Gyawali CP. Parameters on esophageal pH-impedance monitoring that predict outcomes of patients with gastroesophageal reflux disease. Clin Gastroenterol Hepatol 2015;13:884-891.

88. American gastroenterological association medical position statement: guidelines on the use of esophageal $\mathrm{pH}$ recording. Gastroenterology 1996;110:1981.

89. Yano F, Omura N, Tsuboi K, et al. Standard values of 24-h multichannel intraluminal impedance- $\mathrm{pH}$ monitoring for the Japanese. Esophagus 2017;14:91-96.

90. Netinatsunton N, Sottisuporn J, Attasaranya S, et al. i-Scan detection of minimal change esophagitis in dyspeptic patients with or without Gastroesophageal Reflux disease. BMC Gastroenterol 2016;16:4 .

91. Wu JC, Mui LM, Cheung CM, Chan Y, Sung JJ. Obesity is associated with increased transient lower esophageal sphincter relaxation. Gastroenterology 2007;132:883-889.

92. Wu B, Wang M, Li Y. Diagnosis of gastroesophageal reflux disease in elderly subjects using 24-hour esophageal $\mathrm{pH}$ monitoring. Chin Med J (Engl) 1999;112:333-335.

93. Moon W, Park MI, Kim GM, et al. Normal 24-hour Ambulatory Esophageal pH Values in Koreans. Gut Liver 2008;2:8-13.

94. Ferdinandis TG, Dissanayake AS, de Silva HJ. Chronic alcoholism and esophageal motor activity: a 24-h ambulatory manometry study. J Gastroenterol Hepatol 2006;21:1157-1162.

95. Ho KY, Kang JY. Esophageal mucosal acid sensitivity can coexist with normal $\mathrm{pH}$ recording in healthy adult volunteers. J Gastroenterol 2000;35:261-264.

96. Saraswat VA, Dhiman RK, Mishra A, Naik SR. Correlation of 24-hr esophageal $\mathrm{pH}$ patterns with clinical features and endoscopy in gastroesophageal reflux disease. Dig Dis Sci 1994;39:199-205.

97. Kim GH, Huh KC, Lee YC, et al. Normal ambulatory 24-hour esophageal $\mathrm{pH}$ values in Koreans -a multicenter study. J Korean Med Sci 2008;23:954-958.

98. Chun HJ, Lee SW, Choi JH, Kim CD, Ryu HS, Hyun JH. 24 Hour ambulatory esophageal dual probe $\mathrm{pH}$ monitoring in healthy adults. Korean J Gastroenterol 2001;37:1-6.

99. Xiao YL, Liu FQ, Li J, et al. Gastroesophageal and laryngopharyngeal reflux profiles in patients with obstructive sleep apnea/hypopnea syndrome as determined by combined multichannel intraluminal impedance-pH monitoring. Neurogastroenterol Motil 2012;24:e258-e265.
100. Ishimura N, Mori M, Mikami H, et al. Effects of acotiamide on esophageal motor function and gastroesophageal reflux in healthy volunteers. BMC Gastroenterol 2015;15:117.

101. Kawamura O, Kohata Y, Kawami N, et al. Liquid-containing refluxes and acid refluxes may be less frequent in the Japanese population than in other populations: Normal values of 24- hour esophageal impedance and PH monitoring. J Neurogastroenterol Motil 2016;22:620-629.

102. Wang AJ, Liang MJ, Jiang AY, et al. Gastroesophageal and laryngopharyngeal reflux detected by 24-hour combined impedance and $\mathrm{pH}$ monitoring in healthy Chinese volunteers. J Dig Dis 2011;12:173-180.

103. Xiao YL, Lin JK, Cheung TK, et al. Normal values of 24-hour combined esophageal multichannel intraluminal impedance and $\mathrm{pH}$ monitoring in the Chinese population. Digestion 2009;79:109-114.

104. Hu WH, Wong NY, Lai KC, et al. Normal 24-hour ambulatory proximal and distal gastroesophageal reflux parameters in Chinese. Hong Kong Med J 2002;8:168-171.

105. Amarasiri DL, Pathmeswaran A, Dassanayake AS, de Silva AP,Ranasinha CD, de Silva HJ. Esophageal motility, vagal function and gastroesophageal reflux in a cohort of adult asthmatics. BMC Gastroenterol 2012;12:140.

106. Yi CH, Chen CL, Lin HH, Chen MC. Esophageal acid exposure in healthy adults in Taiwan: experience with $\mathrm{pH}$ step-up method by dualchannel pH-metry. Kaohsiung J Med Sci 2005;21:299-303.

107. Kawamura O, Shimoyama Y, Hosaka H, et al. Increase of weakly acidic gas esophagopharyngeal reflux (EPR) and swallowing-induced acidic/ weakly acidic EPR in patients with chronic cough responding to proton pump inhibitors. Neurogastroenterol Motil 2011;23:411-418.

108. Savarino E, Marabotto E, Zentilin P, et al. The added value of impedance-pH monitoring to rome III criteria in distinguishing functional heartburn from non-erosive reflux disease. Dig Liver Dis 2011;43:542547.

109. Prakash C, Clouse RE. Value of extended recording time with wireless $\mathrm{pH}$ monitoring in evaluating gastroesophageal reflux disease. Clin Gastroenterol Hepatol 2005;3:329-334.

110. Ayazi S,Lipham JC, Portale G, et al. Bravo catheter-free $\mathrm{pH}$ monitoring: normal values, concordance, optimal diagnostic thresholds, and accuracy. Clin Gastroenterol Hepatol 2009;7:60-67.

111. Sweis R, Fox M, Anggiansah A, Wong T. Prolonged, wireless pHstudies have a high diagnostic yield in patients with reflux symptoms and negative 24-h catheter-based $\mathrm{pH}$-studies. Neurogastroenterol Motil 2011;23:419-426.

112. Wong WM, Bautista J, Dekel R, et al. Feasibility and tolerability of transnasal/per-oral placement of the wireless $\mathrm{pH}$ capsule vs. traditional 24-h oesophageal $\mathrm{pH}$ monitoring--a randomized trial. Aliment Pharmacol Ther 2005;21:155-163.

113. Sweis R, Fox M, Anggiansah R, et al. Patient acceptance and clinical impact of bravo monitoring in patients with previous failed catheterbased studies. Aliment Pharmacol Ther 2009;29:669-676.

114. Aanen MC, Weusten BL, Numans ME, de Wit NJ, Samsom M, Smout AJ. Effect of proton-pump inhibitor treatment on symptoms and quality of life in GERD patients depends on the symptom-reflux association. J Clin Gastroenterol 2008;42:441-447. 
115. Kushnir VM, Sayuk GS, Gyawali CP. Abnormal GERD parameters on ambulatory $\mathrm{pH}$ monitoring predict therapeutic success in noncardiac chest pain. Am J Gastroenterol 2010;105:1032-1038.

116. Gyawali CP, Sifrim D, Carlson DA, et al. Ineffective esophageal motility: concepts, future directions, and conclusions from the Stanford 2018 symposium. Neurogastroenterol Motil 2019;31:e13584.

117. Shaker A, Stoikes N, Drapekin J, Kushnir V, Brunt LM, Gyawali CP. Multiple rapid swallow responses during esophageal high-resolution manometry reflect esophageal body peristaltic reserve. Am J Gastroenterol 2013;108:1706-1712.

118. Gyawali CP, Roman S, Bredenoord AJ, et al. Classification of esophageal motor findings in gastro-esophageal reflux disease: conclusions from an international consensus group. Neurogastroenterol Motil 2017;29:e13104.

119. Bredenoord AJ, Weusten BL, Timmer R, Smout AJ. Intermittent spatial separation of diaphragm and lower esophageal sphincter favors acidic and weakly acidic reflux. Gastroenterology 2006;130:334-340.

120. Tolone S, De Bortoli N, Marabotto E, et al. Esophagogastric junction contractility for clinical assessment in patients with GERD: a real added value? Neurogastroenterol Motil 2015;27:1423-1431.

121. Ho SC, Chang CS, Wu CY, Chen GH. Ineffective esophageal motility is a primary motility disorder in gastroesophageal reflux disease. Dig Dis Sci 2002;47:652-656.

122. Rengarajan A, Bolkhir A, Gor P, Wang D, Munigala S, Gyawali CP. Esophagogastric junction and esophageal body contraction metrics on high-resolution manometry predict esophageal acid burden. Neurogastroenterol Motil 2018;30:e13267.

123. Reddy CA, Patel A, Gyawali CP. Impact of symptom burden and health-related quality of life (HRQOL) on esophageal motor diagnoses. Neurogastroenterol Motil 2017;29:e12970.

124. Vaezi MF, Sifrim D. Assessing old and new diagnostic tests for gastroesophageal reflux disease. Gastroenterology 2018;154:289-301.

125. Vaezi MF, Choksi Y. Mucosal impedance: a new way to diagnose reflux disease and how it could change your practice. Am J Gastroenterol 2017;112:4-7.

126. Ghisa M, Barberio B, Savarino V, et al. The Lyon consensus: does it differ from the previous ones? J Neurogastroenterol Motil 2020;26:311321.

127. Farré R, Blondeau K, Clement D, et al. Evaluation of oesophageal mucosa integrity by the intraluminal impedance technique. Gut 2011;60:885-892.

128. Ates F, Yuksel ES, Higginbotham T, et al. Mucosal impedance discriminates GERD from non-GERD conditions. Gastroenterology 2015;148:334-343.

129. Frazzoni M, de Bortoli N, Frazzoni L, Tolone S, Savarino V, Savarino E. Impedance-pH monitoring for diagnosis of reflux disease: new perspectives. Dig Dis Sci 2017;62:1881-1889.

130. Frazzoni L, Frazzoni M, de Bortoli N, et al. Postreflux swallow-induced peristaltic wave index and nocturnal baseline impedance can link PPIresponsive heartburn to reflux better than acid exposure time. Neurogastroenterol Motil 2017;29:e13116.

131. Frazzoni M, Savarino E, de Bortoli N, et al. Analyses of the post- reflux swallow-induced peristaltic wave index and nocturnal baseline impedance parameters increase the diagnostic yield of impedance-pH monitoring of patients with reflux disease. Clin Gastroenterol Hepatol 2016;14:40-46.

132. Frazzoni M, de Bortoli N, Frazzoni L, et al. The added diagnostic value of postreflux swallow-induced peristaltic wave index and nocturnal baseline impedance in refractory reflux disease studied with on-therapy impedance-pH monitoring. Neurogastroenterol Motil 2017;29:e12947.

133. El-Serag $\mathrm{H}$. The association between obesity and GERD: a review of the epidemiological evidence. Dig Dis Sci 2008;53:2307-2312.

134. Singh M, Lee J, Gupta N, et al. Weight loss can lead to resolution of gastroesophageal reflux disease symptoms: a prospective intervention trial. Obesity (Silver Spring) 2013;21:284-290.

135. Tack J, Pandolfino JE. Pathophysiology of gastroesophageal reflux disease. Gastroenterology 2018;154:277-288.

136. El-Serag HB, Graham DY, Satia JA, Rabeneck L. Obesity is an independent risk factor for GERD symptoms and erosive esophagitis. Am J Gastroenterol 2005;100:1243-1250.

137. Lee HL, Eun CS, Lee OY, et al. Association between GERD-related erosive esophagitis and obesity. J Clin Gastroenterol 2008;42:672-675.

138. Jung HS, Choi MG, Baeg MK, et al. Obesity is associated with increasing esophageal acid exposure in Korean patients with gastroesophageal reflux disease symptoms. J Neurogastroenterol Motil 2013;19:338-343.

139. Jacobson BC, Somers SC, Fuchs CS, Kelly CP, Camargo CA Jr. Bodymass index and symptoms of gastroesophageal reflux in women. $\mathrm{N}$ Engl J Med 2006;354:2340-2348.

140. Eusebi LH, Ratnakumaran R, Yuan Y, Solaymani-Dodaran M, Bazzoli F, Ford AC. Global prevalence of, and risk factors for, gastro-oesophageal reflux symptoms: a meta-analysis. Gut 2018;67:430-440.

141. de Bortoli N, Guidi G, Martinucci I, et al. Voluntary and controlled weight loss can reduce symptoms and proton pump inhibitor use and dosage in patients with gastroesophageal reflux disease: a comparative study. Dis Esophagus 2016;29:197-204.

142. Ness-Jensen E, Lindam A, Lagergren J, Hveem K. Weight loss and reduction in gastroesophageal reflux. A prospective population-based cohort study: the HUNT study. Am J Gastroenterol 2013;108:376-382.

143. Mathus-Vliegen EM, Tygat GN. Gastro-oesophageal reflux in obese subjects: influence of overweight, weight loss and chronic gastric balloon distension. Scand J Gastroenterol 2002;37:1246-1252.

144. Fraser-Moodie CA, Norton B, Gornall C, Magnago S, Weale AR, Holmes GK. Weight loss has an independent beneficial effect on symptoms of gastro-oesophageal reflux in patients who are overweight. Scand J Gastroenterol 1999;34:337-340.

145. Kjellin A, Ramel S, Rössner S, Thor K. Gastroesophageal reflux in obese patients is not reduced by weight reduction. Scand J Gastroenterol 1996;31:1047-1051.

146. Park SK, Lee T, Yang HJ, et al. Weight loss and waist reduction is associated with improvement in gastroesophageal disease reflux symptoms: a longitudinal study of 15295 subjects undergoing health checkups. Neurogastroenterol Motil 2017;29:e13009.

147. Bang KB, Park JH. Weight loss as a nonpharmacologic strategy for erosive esophagitis: a 5-year follow-up study. Gut Liver 2018;12:633-640. 
148. Cremonini F, Locke GR 3rd, Schleck CD, Zinsmeister AR, Talley NJ. Relationship between upper gastrointestinal symptoms and changes in body weight in a population-based cohort. Neurogastroenterol Motil 2006;18:987-994.

149. Dickman R, Maradey-Romero C, Gingold-Belfer R, Fass R. Unmet needs in the treatment of gastroesophageal reflux disease. J Neurogastroenterol Motil 2015;21:309-319.

150. Chiba N, De Gara CJ, Wilkinson JM, Hunt RH. Speed of healing and symptom relief in grade II to IV gastroesophageal reflux disease: a metaanalysis. Gastroenterology 1997;112:1798-1810.

151. van Pinxteren B, Sigterman KE, Bonis P, Lau J, Numans ME. Shortterm treatment with proton pump inhibitors, $\mathrm{H} 2$-receptor antagonists and prokinetics for gastro-oesophageal reflux disease-like symptoms and endoscopy negative reflux disease. Cochrane Database Syst Rev 2010:CD002095.

152. Richter JE, Kahrilas PJ, Johanson J, et al. Efficacy and safety of esomeprazole compared with omeprazole in GERD patients with erosive esophagitis: a randomized controlled trial. Am J Gastroenterol 2001;96:656-665.

153. Sigterman KE, van Pinxteren B, Bonis PA, Lau J, Numans ME. Shortterm treatment with proton pump inhibitors, H2-receptor antagonists and prokinetics for gastro-oesophageal reflux disease-like symptoms and endoscopy negative reflux disease. Cochrane Database Syst Rev 2013;2013:CD002095.

154. Kinoshita Y, Hongo M. Efficacy of twice-daily rabeprazole for reflux esophagitis patients, refractory to standard once-daily administration of PPI: the Japan-based TWICE study. Am J Gastroenterol 2012;107:522-530.

155. Orlando RC, Liu S, Illueca M. Relationship between esomeprazole dose and timing to heartburn resolution in selected patients with gastroesophageal reflux disease. Clin Exp Gastroenterol 2010;3:117-125.

156. Fass R, Sontag SJ, Traxler B, Sostek M. Treatment of patients with persistent heartburn symptoms: a double-blind, randomized trial. Clin Gastroenterol Hepatol 2006;4:50-56.

157. Gralnek IM, Dulai GS, Fennerty MB, Spiegel BM. Esomeprazole versus other proton pump inhibitors in erosive esophagitis: a meta-analysis of randomized clinical trials. Clin Gastroenterol Hepatol 2006;4:14521458 .

158. Zhang C, Kwong JS, Yuan RX, et al. Effectiveness and tolerability of different recommended doses of PPIs and H2RAs in GERD: network meta-analysis and GRADE system. Sci Rep 2017;7:41021.

159. Hetzel DJ, Dent J, Reed WD, et al. Healing and relapse of severe peptic esophagitis after treatment with omeprazole. Gastroenterology 1998;95:903-912.

160. Hojo M, Nagahara A, Hahm KB, et al. Management of gastroesophageal reflux disease in Asian countries: results of a questionnaire survey. Digestion 2020;101:66-79.

161. Jung HK, Hong Sj, Jo YJ, et al. [Updated guidelines 2012 for gastroesophageal reflux disease.] Korean J Gastroenterol 2012;60:195-218. [Korean]

162. Katz PO, Gerson LB, Vela MF. Guidelines for the diagnosis and management of gastroesophageal reflux disease. Am J Gastroenterol
2013;108:308-328.

163. Hunt R, Armstrong D, Katelaris P, et al. World gastroenterology organisation global guidelines: GERD Global perspective on gastroesophageal reflux disease. J Clin Gastroenterol 2017;51:467-478.

164. Chung SJ, Kim SG, Jung HC, Song IS, Kim JS. [Clinical practice patterns of gastroenterologists for initial and maintenance therapy in gastroesophageal reflux disease: a nationwide online survey in Korea.] Korean J Gastroenterol 2009;54:364-3670. [Korean]

165. Bayerdörffer E, Bigard MA, Weiss W, et al. Randomized, multicenter study: on-demand versus continuous maintenance treatment with esomeprazole in patients with non-erosive gastroesophageal reflux disease. BMC Gastroenterol 2016;16:48.

166. van der Velden AW, de Wit NJ, Quartero AO, Grobbee DE, Numans ME. Pharmacological dependency in chronic treatment of gastroesophageal reflux disease: a randomized controlled clinical trial. Digestion 2010;81:43-52.

167. Szucs T, Thalmann C, Michetti P, Beglinger C. Cost analysis of longterm treatment of patients with symptomatic gastroesophageal reflux disease (GERD) with esomeprazole on-demand treatment or esomeprazole continuous treatment: an open, randomized, multicenter study in Switzerland. Value Health 2009;12:273-281.

168. Morgan DG, O’Mahony MF, O’Mahony WF, et al. Maintenance treatment of gastroesophageal reflux disease: an evaluation of continuous and on-demand therapy with rabeprazole $20 \mathrm{mg}$. Can J Gastroenterol 2007;21:820-826.

169. Sjöstedt S, Befrits R, Sylvan A, et al. Daily treatment with esomeprazole is superior to that taken on-demand for maintenance of healed erosive oesophagitis. Aliment Pharmacol Ther 2005;22:183-191.

170. Norman Hansen A, Bergheim R, Fagertun H, Lund H, Moum B. A randomised prospective study comparing the effectiveness of esomeprazole treatment strategies in clinical practice for 6 months in the management of patients with symptoms of gastroesophageal reflux disease. Int J Clin Pract 2005;59:665-671.

171. Janssen W, Meier E, Gatz G, Pfaffenberger B. Effects of pantoprazole $20 \mathrm{mg}$ in mild gastroesophageal reflux disease: once-daily treatment in the acute phase, and comparison of on-demand versus continuous treatment in the long term. Curr Ther Res Clin Exp 2005;66:345-363.

172. Achem SR, Kolts BE, MacMath T, et al. Effects of omeprazole versus placebo in treatment of noncardiac chest pain and gastroesophageal reflux. Dig Dis Sci 1997;42:2138-2145.

173. Bautista J, Fullerton H, Briseno M, Cui H, Fass R. The effect of an empirical trial ofhigh-dose lansoprazole on symptom response of patients with non-cardiac chest pain--a randomized, double-blind, placebo-controlled, crossover trial. Aliment Pharmacol Ther 2004;19:1123-1130.

174. Dickman R, Emmons S, Cui H, et al. The effect of a therapeutic trial of high-dose rabeprazole on symptom response of patients with non-cardiac chest pain: a randomized, double-blind, placebo-controlled, crossover trial. Aliment Pharmacol Ther 2005;22:547-555.

175. Fass R, Fennerty MB, Ofman JJ, et al. The clinical and economic value of a short course of omeprazole in patients with noncardiac chest pain. Gastroenterology 1998;115:42-49.

176. Flook NW, Moayyedi P, Dent J, et al. Acid-suppressive therapy with 
esomeprazole for relief of unexplained chest pain in primary care: a randomized, double-blind, placebo-controlled trial. Am J Gastroenterol 2013;108:56-64.

177. Pandak WM, Arezo S, Everett S, et al. Short course of omeprazole: a better first diagnostic approach to noncardiac chest pain than endoscopy, manometry, or 24-hour esophageal $\mathrm{pH}$ monitoring. J Clin Gastroenterol 2002;35:307-314.

178. Xia HH, Lai KC, Lam SK, et al. Symptomatic response to lansoprazole predicts abnormal acid reflux in endoscopy-negative patients with noncardiac chest pain. Aliment Pharmacol Ther 2003;17:369-377.

179. Shaheen NJ, Falk GW, Iyer PG, Gerson LB. ACG clinical guideline: diagnosis and management of barrett's esophagus. Am J Gastroenterol 2016;111:30-50.

180. Singh S, Garg SK, Singh PP, Iyer PG, El-Serag HB. Acid-suppressive medications and risk of oesophageal adenocarcinoma in patients with Barrett's oesophagus: a systematic review and meta-analysis. Gut 2014;63:1229-1237.

181. Hu Q, Sun TT, Hong J, Fang JY, Xiong H, Meltzer SJ. Proton pump inhibitors do not reduce the risk of esophageal adenocarcinoma in patients with Barrett's esophagus: a systematic review and meta-analysis. PLoS One 2017;12:e0169691.

182. Spechler SJ, Sharma P, Souza RF, Inadomi JM, Shaheen NJ. American gastroenterological association technical review on the management of barrett's esophagus. Gastroenterology 2011;140:e18-e52.

183. de Jonge PJ, Steyerberg EW, Kuipers EJ, et al. Risk factors for the development of esophageal adenocarcinoma in Barrett's esophagus. Am J Gastroenterol 2006;101:1421-1429.

184. Masclee GM, Coloma PM, Spaander MC, Kuipers EJ, Sturkenboom MC. NSAIDs, statins, low-dose aspirin and PPIs, and the risk of oesophageal adenocarcinoma among patients with Barrett's oesophagus: a population-based case-control study. BMJ Open 2015;5:e066640.

185. Tan MC, El-Serag HB, Yu X, Thrift AP. Acid suppression medications reduce risk of oesophageal adenocarcinoma in Barrett's oesophagus: a nested case-control study in US male veterans. Aliment Pharmacol Ther 2018;48:469-477.

186. Hillman LC, Chiragakis L, Shadbolt B, Kaye GL, Clarke AC. Protonpump inhibitor therapy and the development of dysplasia in patients with Barrett's oesophagus. Med J Aust 2004;180:387-391.

187. Nguyen DM, El-Serag HB, Henderson L, Stein D, Bhattacharyya A, Sampliner RE. Medication usage and the risk of neoplasia in patients with Barrett's esophagus. Clin Gastroenterol Hepatol 2009;7:12991304.

188. Jung KW, Talley NJ, Romero Y, et al. Epidemiology and natural history of intestinal metaplasia of the gastroesophageal junction and Barrett's esophagus: a population-based study. Am J Gastroenterol 2011;106:1447-1455.

189. Kastelein F, Spaander MC, Steyerberg EW, et al. Proton pump inhibitors reduce the risk of neoplastic progression in patients with Barrett's esophagus. Clin Gastroenterol Hepatol 2013;11:382-388.

190. Krishnamoorthi R, Borah B, Heien H, Das A, Chak A, Iyer PG. Rates and predictors of progression to esophageal carcinoma in a large population-based Barrett's esophagus cohort. Gastrointest Endosc 2016;84:40-
46, e7.

191. Neal KR, Scott HM, Slack RC, Logan RF. Omeprazole as a risk factor for campylobacter gastroenteritis: case-control study. BMJ 1996;312:414-415.

192. Loo VG, Bourgault AM, Poirier L, et al. Host and pathogen factors for Clostridium difficile infection and colonization. N Engl J Med 2011;365:1693-1703.

193. Moayyedi P, Eikelboom JW, Bosch J, et al. Safety of proton pump inhibitors based on a large, multi-year, randomized trial of patients receiving rivaroxaban or aspirin. Gastroenterology 2019;157:682-691, e2.

194. Oshima T, Wu L, Li M, Fukui H, Watari J, Miwa H. Magnitude and direction of the association between Clostridium difficile infection and proton pump inhibitors in adults and pediatric patients: a systematic review and meta-analysis. J Gastroenterol 2018;53:84-94.

195. Furuya-Kanamori L, Stone JC, Clark J, et al. Comorbidities, exposure to medications, and the risk of community-acquired Clostridium difficile infection: a systematic review and meta-analysis. Infect Control Hosp Epidemiol 2015;36:132-141.

196. Arriola V, Tischendorf J, Musuuza J, Barker A, Rozelle JW, Safdar N. Assessing the risk of hospital-acquired Clostridium difficile infection with proton pump inhibitor use: a meta-analysis. Infect Control Hosp Epidemiol 2016;37:1408-1417.

197. Tariq R, Singh S, Gupta A, Pardi DS, Khanna S. Association of gastric acid suppression with recurrent Clostridium difficile infection: a systematic review and meta-analysis. JAMA Intern Med 2017;177:784-791.

198. Trifan A, Stanciu C, Girleanu I, et al. Proton pump inhibitors therapy and risk of Clostridium difficile infection: systematic review and metaanalysis. World J Gastroenterol 2017;23:6500-6515.

199. Cao F, Chen CX, Wang M, et al. Updated meta-analysis of controlled observational studies: proton-pump inhibitors and risk of Clostridium difficile infection. J Hosp Infect 2018;98:4-13.

200. Beil W, Hackbarth I, Sewing KF. Mechanism of gastric antisecretory effect of SCH 28080. Br J Pharmacol1986;88:19-23.

201. Oshima T, Miwa H. Potent potassium-competitive acid blockers: a new era for the treatment of acid-related diseases. J Neurogastroenterol Motil 2018;24:334-344.

202. Xiao Y, Zhang S, Dai N, et al. Phase III, randomized, double-blind, multicentre study to evaluate the efficacy and safety of vonoprazan compared with lansoprazole in Asian patients with erosive oesophagitis. Gut 2020;69:224-230.

203. Ashida K, Sakurai Y, Hori T, et al. Randomized clinical trial: vonoprazan, a novel potassium-competitive acid blocker, vs. lansoprazole for the healing of erosive oesophagitis. Aliment Pharmacol Ther 2016;43:240251.

204. Ashida K, Sakurai Y, Nishimura A, et al. Randomized clinical trial: adose-ranging study of vonoprazan, a novel potassium-competitive acid blocker, vs. lansoprazole for the treatment of erosive oesophagitis. Aliment Pharmacol Ther 2015;42:685-695.

205. Miyazaki H, Igarashi A, Takeuchi T, et al. Vonoprazan versus protonpump inhibitors for healing gastroesophageal reflux disease: a systematic review. J Gastroenterol Hepatol 2019;34:1316-1328.

206. Lee KJ, Son BK, Kim GH, et al. Randomized phase 3 trial: tegoprazan, 
a novel potassium-competitive acid blocker, vs. esomeprazole in patients with erosive oesophagitis. Aliment Pharmacol Ther 2019;49:864-872.

207. Kim DK, Lee KH, Kim SJ, et al. Effects of tegoprazan, a novel potassium-competitive acid blocker, on rat models of gastric acid-related disease. J Pharmacol Exp Ther 2019;369:318-327.

208. Han S, Choi HY, Kim YH, et al. Randomized clinical trial: safety, tolerability, pharmacokinetics, and pharmacodynamics of single and multiple oral doses of tegoprazan (CJ-12420), a novel potassium-competitive acid blocker, in healthy male subjects. Aliment Pharmacol Ther 2019;50:751759.

209. Takahashi N, Take Y. Tegoprazan, a novel potassium-competitive acid blocker to control gastric acid secretion and motility. J Pharmacol Exp Ther 2018;364:275-286.

210. Peghini PL, Katz PO, Bracy NA, Castell DO. Nocturnal recovery of gastric acid secretion with twice-daily dosing of proton pump inhibitors. Am J Gastroenterol 1998;93:763-767.

211. Savarino V, Di Mario F, Scarpignato C. Proton pump inhibitors in GORD an overview of their pharmacology, efficacy and safety. Pharmacol Res 2009;59:135-153.

212. Rackoff A, Agrawal A, Hila A, Mainie I, Tutuian R, Castell DO. Histamine-2 receptor antagonists at night improve gastroesophageal reflux disease symptoms for patients on proton pump inhibitor therapy. Dis Esophagus 2005;18:370-373.

213. Mainie I, Tutuian R, Castell DO. Addition of a $\mathrm{H} 2$ receptor antagonist to PPI improves acid control and decreases nocturnal acid breakthrough. J Clin Gastroenterol 2008;42:676-679.

214. Peghini PL, Katz PO, Castell DO. Ranitidine controls nocturnal gastric acid breakthrough on omeprazole: a controlled study in normal subjects. Gastroenterology 1998;115:1335-1339.

215. Khoury RM, Katz PO, Hammod R, Castell DO. Bedtime ranitidine does not eliminate the need for a second daily dose of omeprazole to suppress nocturnal gastric $\mathrm{pH}$. Aliment Pharmacol Ther 1999;13:675-678.

216. Janiak P, Thumshirn M, Menne D, et al. Clinical trial: the effects of adding ranitidine at night to twice daily omeprazole therapy on nocturnal acid breakthrough and acid reflux in patients with systemic sclerosis-a randomized controlled, cross-over trial. Aliment Pharmacol Ther 2007;26:1259-1265.

217. Wang Y, Pan T, Wang Q, Guo Z. Additional bedtime H2-receptor antagonist for the control of nocturnal gastric acid breakthrough. Cochrane Database Syst Rev 2009:Cd004275.

218. Fackler WK, Ours TM, Vaezi MF, Richter JE. Long-term effect of H2RA therapy on nocturnal gastric acid breakthrough. Gastroenterology 2002;122:625-632.

219. Fass R, Shapiro M, Dekel R, Sewell J. Systematic review: proton-pump inhibitor failure in gastro-oesophageal reflux disease--where next? Aliment Pharmacol Ther 2005;22:79-94.

220. Miwa H, Inoue K, Ashida K, et al. Randomized clinical trial: efficacy of the addition of a prokinetic, mosapride citrate, to omeprazole in the treatment of patients with non-erosive reflux disease - a double-blind, placebo-controlled study. Aliment Pharmacol Ther 2011;33:323-332.

221. Miyamoto M, Manabe N, Haruma K. Efficacy of the addition of prokinetics for proton pump inhibitor (PPI) resistant non-erosive reflux disease (NERD) patients: significance of frequency scale for the symptom of GERD (FSSG) on decision of treatment strategy. Intern Med 2010;49:1469-1476.

222. Liu Q, Feng CC, Wang EM, Yan XJ, Chen SL. Efficacy of mosapride plus proton pump inhibitors for treatment of gastroesophageal reflux disease: a systematic review. World J Gastroenterol 2013;19:9111-9118.

223. Grossi L, Spezzaferro M, Sacco LF, Marzio L. Effect of baclofen on oesophageal motility and transient lower oesophageal sphincter relaxations in GORD patients: a 48-h manometric study. Neurogastroenterol Motil 2008;20:760-766.

224. Koek GH, Sifrim D, Lerut T, Janssens J, Tack J. Effect of the GABA(B) agonist baclofen in patients with symptoms and duodenogastro-oesophageal reflux refractory to proton pump inhibitors. Gut 2003;52:1397-1402.

225. van Herwaarden MA, Samsom M, Rydholm H, Smout AJ. The effect of baclofen on gastro-oesophageal reflux, lower oesophageal sphincter function and reflux symptoms in patients with reflux disease. Aliment Pharmacol Ther 2002;16:1655-1662.

226. Ciccaglione AF, Marzio L. Effect of acute and chronic administration of the GABA B agonist baclofen on 24 hour $\mathrm{pH}$ metry and symptoms in control subjects and in patients with gastro-oesophageal reflux disease. Gut 2003;52:464-470.

227. Cossentino MJ, Mann K, Armbruster SP, Lake JM, Maydonovitch C, Wong RK. Randomized clinical trial: the effect of baclofen in patients with gastro-oesophageal reflux--a randomized prospective study. Aliment Pharmacol Ther 2012;35:1036-1044.

228. Cange L, Johnsson E, Rydholm H, et al. Baclofen-mediated gastrooesophageal acid reflux control in patients with established reflux disease. Aliment Pharmacol Ther 2002;16:869-873.

229. Li S, Shi S, Chen F, Lin J. The effects of baclofen for the treatment of gastroesophageal reflux disease: a meta-analysis of randomized controlled trials. Gastroenterol Res Pract 2014;2014:307805.

230. Sandhu DS, Fass R. Current trends in the management of gastroesophageal reflux disease. Gut Liver 2018;12:7-16.

231. Mandel KG, Daggy BP, Brodie DA, Jacoby HI. Review article: alginate-raft formulations in the treatment of heartburn and acid reflux. Aliment Pharmacol Ther 2000;14:669-690.

232. Kahrilas PJ, McColl K, Fox M, et al. The acid pocket: a target for treatment in reflux disease? Am J Gastroenterol 2013;108:1058-1064.

233. Kwiatek MA, Roman S, Fareeduddin A, Pandolfino JE, Kahrilas PJ. An alginate-antacid formulation (gaviscon double action liquid) can eliminate or displace the postprandial 'acid pocket' in symptomatic GERD patients. Aliment Pharmacol Ther 2011;34:59-66.

234. Thomas E, Wade A, Crawford G, Jenner B, Levinson N, Wilkinson J. Randomized clinical trial: relief of upper gastrointestinal symptoms by an acid pocket-targeting alginate-antacid (gaviscon double action) - a double-blind, placebo-controlled, pilot study in gastro-oesophageal reflux disease. Aliment Pharmacol Ther 2014;39:595-602.

235. Savarino E, de Bortoli N, Zentilin P, et al. Alginate controls heartburn in patients with erosive and nonerosive reflux disease. World J Gastroenterol 2012;18:4371-4378.

236. Yuan YZ, Fang JY, Zou DW, Levinson N, Jenner B, Wilkinson J. Al- 
ginate antacid (Gaviscon DA) chewable tablets reduce esophageal acid exposure in Chinese patients with gastroesophageal reflux disease and heartburn symptoms. J Dig Dis 2016;17:725-734.

237. De Ruigh A, Roman S, Chen J, Pandolfino JE, Kahrilas PJ. Gaviscon double action liquid (antacid \& alginate) is more effective than antacid in controlling post-prandial oesophageal acid exposure in GERD patients: a double-blind crossover study. Aliment Pharmacol Ther 2014;40:531537.

238. Wilkinson J, Wade A, Thomas SJ, Jenner B, Hodgkinson V, Coyle C. Randomized clinical trial: a double-blind, placebo-controlled study to assess the clinical efficacy and safety of alginate-antacid (gaviscon double action) chewable tablets in patients with gastro-oesophageal reflux disease. Eur J Gastroenterol Hepatol 2019;31:86-93.

239. Lai IR, Wu MS, Lin JT. Prospective, randomized, and active controlled study of the efficacy of alginic acid and antacid in the treatment of patients with endoscopy-negative reflux disease. World J Gastroenterol 2006;12:747-754.

240. Tran T, Lowry AM, El-Serag HB. Meta-analysis: the efficacy of overthe-counter gastro-oesophageal reflux disease therapies. Aliment Pharmacol Ther 2007;25:143-153.

241. Chiu CT, Hsu CM, Wang CC, et al. Randomized clinical trial: sodium alginate oral suspension is non-inferior to omeprazole in the treatment of patients with non-erosive gastroesophageal disease. Aliment Pharmacol Ther 2013;38:1054-1064.

242. Coyle C, Crawford G, Wilkinson J, Thomas SJ, Bytzer P. Randomized clinical trial: addition of alginate-antacid (gaviscon double action) to proton pump inhibitor therapy in patients with breakthrough symptoms. Aliment Pharmacol Ther 2017;45:1524-1533.

243. Kim JH, Lee YC, Kim EH, et al. The clinical efficacy of a pure alginate formulation (lamina g) for controlling symptoms in individuals with reflux symptoms: a randomized clinical study. Gut Liver 2019;13:642648.

244. Reimer C, Lødrup AB, Smith G, Wilkinson J, Bytzer P. Randomized clinical trial: alginate (gaviscon advance) vs. placebo as add-on therapy in reflux patients with inadequate response to a once daily proton pump inhibitor. Aliment Pharmacol Ther 2016;43:899-909.

245. Leiman DA, Riff BP, Morgan S, et al. Alginate therapy is effective treatment for GERD symptoms: a systematic review and meta-analysis. Dis Esophagus 2017;30:1-9.

246. Fass R, Cahn F, Scotti DJ, Gregory DA. Systematic review and metaanalysis of controlled and prospective cohort efficacy studies of endoscopic radiofrequency for treatment of gastroesophageal reflux disease. Surg Endosc 2017;31:4865-4882.

247. Lipka S, Kumar A, Richter JE. No evidence for efficacy of radiofrequency ablation for treatment of gastroesophageal reflux disease: a systematic review and meta-analysis. Clin Gastroenterol Hepatol 2015;13:1058-1067, e1.

248. Perry KA, Banerjee A, Melvin WS. Radiofrequency energy delivery to the lower esophageal sphincter reduces esophageal acid exposure and improves GERD symptoms: a systematic review and meta-analysis. Surg Laparosc Endosc Percutan Tech 2012;22:283-288.
249. Noar M, Squires P, Noar E, Lee M. Long-term maintenance effect of radiofrequency energy delivery for refractory GERD: a decade later. Surg Endosc 2014;28:2323-2333.

250. Lundell L, Miettinen P, Myrvold HE, et al. Continued (5-year) followup of a randomized clinical study comparing antireflux surgery and omeprazole in gastroesophageal reflux disease. J Am Coll Surg 2001;192:172-179; discussion 179-181.

251. Lundell L, Miettinen P, Myrvold HE, et al. Seven-year follow-up of a randomized clinical trial comparing proton-pump inhibition with surgical therapy for reflux oesophagitis. Br J Surg 2007;94:198-203.

252. Myrvold HE, Lundell L, Miettinen P, et al. The cost of long-term therapy for gastro-oesophageal reflux disease: a randomized trial comparing omeprazole and open antireflux surgery. Gut 2001;49:488-494.

253. Mehta S, Bennett J, Mahon D, Rhodes M. Prospective trial of laparoscopic nissen fundoplication versus proton pump inhibitor therapy for gastroesophageal reflux disease: seven-year follow-up. J Gastrointest Surg 2006;10:1312-1316; discussion 1316-1317.

254. Anvari M, Allen C, Marshall J, et al. A randomized controlled trial of laparoscopic nissen fundoplication versus proton pump inhibitors for the treatment of patients with chronic gastroesophageal reflux disease (GERD): 3-year outcomes. Surg Endosc 2011;25:2547-2554.

255. Cookson R, Flood C, Koo B, Mahon D, Rhodes M. Short-term cost effectiveness and long-term cost analysis comparing laparoscopic nissen fundoplication with proton-pump inhibitor maintenance for gastrooesophageal reflux disease. Br J Surg 2005;92:700-706.

256. Epstein D, Bojke L, Sculpher MJ. Laparoscopic fundoplication compared with medical management for gastro-oesophageal reflux disease: cost effectiveness study. BMJ 2009;339:b2576.

257. Grant AM, Boachie C, Cotton SC, et al. Clinical and economic evaluation of laparoscopic surgery compared with medical management for gastro-oesophageal reflux disease: 5-year follow-up of multicentre randomized trial (the REFLUX trial). Health Technol Assess 2013;17:1167.

258. Hatlebakk JG, Zerbib F, Bruley des Varannes S, et al. Gastroesophageal acid reflux control 5 years after antireflux surgery, compared with longterm esomeprazole therapy. Clin Gastroenterol Hepatol 2016;14:678685, e3.

259. Emken BG, Lundell LR, Wallin L, et al. Effects of omeprazole or anti-reflux surgery on lower oesophageal sphincter characteristics and oesophageal acid exposure over 10 years. Scand J Gastroenterol 2017;52:11-17.

260. Park S, Park S, Park JM, et al. Anti-reflux surgery versus proton pump inhibitors for severe gastroesophageal reflux disease: a cost-effectiveness study in Korea. J Neurogastroenterol Motil 2020;26:215-223.

261. Mahon D, Rhodes M, Decadt B, et al. Randomized clinical trial of laparoscopic nissen fundoplication compared with proton-pump inhibitors for treatment of chronic gastro-oesophageal reflux. Br J Surg 2005;92:695-699.

262. Grant AM, Wileman SM, Ramsay CR, et al. Minimal access surgery compared with medical management for chronic gastro-oesophageal reflux disease: UK collaborative randomised trial. BMJ 2008;337:a2664. 